Last updated: 6/4/2020

\title{
Structural Solidarity: Lay Theories of Discrimination and Coalitional Attitudes among Stigmatized Groups
}

Maureen A. Craig ${ }^{1}$, Julian M. Rucker ${ }^{2}$, \& Riana M. Brown ${ }^{1}$

${ }^{1}$ Department of Psychology, New York University

${ }^{2}$ Department of Psychology, Yale University

\section{Author note}

The authors gratefully acknowledge the support of NSF grant BCS-1823840 awarded to the first author.

*Please send correspondence to Maureen A. Craig, Department of Psychology, New York University, 6 Washington Place, New York, NY 10003 (e-mail: maureen.craig@nyu.edu).

9794 word count $=$ Abstract (150), Main text (8572), Open Science (19), References (973), and Footnotes (80) 


\begin{abstract}
How do people's beliefs about what drives discrimination against their group (structural factors or interpersonal biases) affect their support for coalescing with and improving stigmatized outgroups' positions? Analyses of nationally-representative datasets reveal that Hispanics, Black Americans, and White women who held more structural (vs. interpersonal) understandings of ingroup discrimination (racism, sexism) were more likely to express support and attend to issues affecting other stigmatized groups (Study 1). Among White women and nonBlack LGBTQ individuals, beliefs that structural factors drive the ingroup's discrimination predicted support for intra-minority coalitions and intentions and behavior supporting Black Americans (Study 2). Finally, several experiments (Studies 3-4) revealed that White women for whom structural forms of sexism (vs. interpersonally-driven sexism or control information) were made salient expressed more support for coalescing with and acting to support racial minority groups. Overall, considering structural factors contributing to discrimination against one's own group's facilitates seeking and supporting intra-minority coalitions.

Keywords: stigma-based solidarity; intra-minority intergroup relations; minority groups; structural discrimination; lay theories of discrimination
\end{abstract}




\section{Structural Solidarity: Lay Theories of Discrimination and Coalitional Attitudes among Stigmatized Groups}

In the last decade, Americans belonging to many different social groups (e.g., race, gender, religion) engaged in movements raising awareness of systemic inequality and discrimination across a number of dimensions. The \#BlackLivesMatter movement emerged in 2013, protesting perceived racial injustice within the criminal justice system. The 2017 Women's Marches marked the largest single day of protest in United States history, as hundreds of thousands of individuals protested anticipated policy changes to be implemented in the new presidential administration (Broomfield, 2017). Many of these social movements highlight the role of broader systemic and institutional factors in driving social inequality (a structural view), which is quite distinct from the perspective that individuals' biases and prejudices drive inequality (an interpersonal view). Given the heightened political mobilization of members of different culturally-devalued (i.e., stigmatized) groups, the present research empirically tests how individuals' beliefs about the drivers of inequality and discrimination faced by their own group (e.g., biased institutional practices or biased individuals) influence support for coalitions among stigmatized groups and support for action to aid stigmatized outgroups.

\section{Lay Theories of Discrimination}

Several forms of discrimination are often cited as contributing to intergroup inequality (e.g., Link \& Phelan, 2001; Pincus, 1996). Of particular relevance to the present research, interpersonal discrimination occurs when individuals discriminate due to their negative attitudes and stereotypes regarding stigmatized groups (e.g., offering a lower starting salary to women due to stereotypical beliefs). Structural discrimination, in 
contrast, occurs when institutional policies, societal practices, and norms detrimentally impact stigmatized groups, regardless of individuals' attitudes (e.g., using salary history in hiring negotiations perpetuates the gender pay gap). People may perceive that intergroup inequality is driven by interpersonal biases and stereotypes, by institutional or systemic practices that disadvantage groups, or they may hold beliefs that both forms of discrimination contribute to inequality.

Given the different forms of discrimination that individuals may consider when making sense of intergroup inequality, how might the consideration of structural (vs. interpersonal) discrimination influence group-relevant attitudes and behaviors? Some evidence suggests that the extent to which members of stigmatized groups perceive that structural factors contribute to their group's inequality predicts affiliation with their ingroup. For example, among racial minority group members, whereas experiences of interpersonal discrimination are associated with social withdrawal (Tawa et al., 2012; Utsey et al., 2000), experiences of structural discrimination predict greater collective selfesteem (Tawa et al., 2012). Moreover, among African Americans, denying structural racism predicts lower racial group identification, greater attributions of African Americans' lower status to individual failings instead of systemic discrimination, and greater endorsement of negative group stereotypes (Neville et al., 2005). Thus, this research suggests that considering structural discrimination faced by one's own group can facilitate ingroup affiliation. Might considering structural discrimination faced by one's own group also facilitate support for affiliation and solidarity with other stigmatized groups? To gain insight into this question, we next turn to the burgeoning literature 
examining how perceptions of discrimination can influence relations among stigmatized groups.

\section{Stigma-Based Solidarity}

A growing literature has developed that examines how people's perceptions that their own group faces discrimination may influence their attitudes toward other stigmatized groups (for recent theoretical reviews, see Craig \& Richeson, 2016; Richeson \& Craig, 2011; Vollhardt, 2015). This research reveals that perceiving that one's group faces discrimination can lead to the derogation of stigmatized outgroups in an effort to bolster one's group esteem (Craig et al., 2012; Craig \& Richeson, 2014). However, if the experiences of discrimination faced by different stigmatized groups are construed as shared (see Sellers et al., 1997; Vollhardt, 2015), considering one’s own group's discrimination can activate a shared sense of identity, leading to positivity toward other stigmatized groups (Cortland et al., 2017; Craig \& Richeson, 2012; Vollhardt et al., 2016). A key question then, is under what circumstances do stigmatized group members perceive commonality between their experiences with discrimination and those of other stigmatized groups?

In recent qualitative work relevant to this question, interviews conducted with social activists reveal that awareness of structural disadvantages faced by one's own group predicts perceived commonality with other stigmatized groups (Curtin et al., 2016). Examining this association from the other direction, awareness of how different forms of inequality may relate and are similar to one another (i.e., intersectional awareness) positively predicts increased likelihood of activism in support of multiple stigmatized groups (Curtin et al., 2015). Additionally, experimental work finds that accentuating 
shared aspects of different groups' discrimination experiences can facilitate coalitional attitudes. For example, connecting past racial discrimination to recent discrimination against sexual minorities (e.g., moralized arguments against marriage rights) leads straight racial minority group members to express positivity toward and support for policies affecting sexual minorities (Cortland et al., 2017). Importantly, while the shared experiences of discrimination highlighted in this work included examples of societal structures and institutions that disadvantage groups (e.g., marriage laws), the experimental primes highlighted the shared stereotypes and moral arguments used to express favorability toward those laws and justify differential treatment (i.e., individually-held attitudes and stereotypes). Thus, no prior work (to our knowledge) has experimentally manipulated structural and interpersonal explanations of group inequality to empirically test the possibility that considering structural discrimination may facilitate solidarity among stigmatized groups. The present research compares the unique influences of structural and interpersonal explanations of ingroup inequality, both experimentally and correlationally, to empirically test the possibility that holding beliefs that discrimination against one's own group's is structurally driven may increase individuals' support for coalescing and solidarity with stigmatized outgroups.

\section{Why Structural Discrimination May Facilitate Support for Solidarity}

In addition to testing whether a structural (vs. interpersonal) understanding of the discrimination faced by one's own group may facilitate support for intra-minority solidarity, the present research provides an initial inquiry as to why this may be the case. We test for two potential underlying psychological mechanisms: increases in the perceived pervasiveness of discrimination and changes in psychological abstraction. Prior 
work suggests that raising awareness of structural discrimination does not reduce perceptions of individual-level discrimination (see Adams et al., 2008). Thus, highlighting structural discrimination may increase the perceived pervasiveness of discrimination as individuals may be aware of both interpersonal and structural factors contributing to inequality, ultimately highlighting perceived need for coalescing among members of different stigmatized groups. The expansion in the perceived pervasiveness of discrimination could lead individuals to seek coalition partners and support one another to address their common goals (possibly in an instrumental manner, see Segura, 2006).

Another potential underlying mechanism investigated in the present workpsychological abstraction - draws from construal level theory (Liberman \& Trope, 2008; Trope \& Liberman, 2010), which posits that events and concepts can be considered along a continuum of abstraction. At high levels of abstraction, individuals focus on the central features of an object or category and at low levels of abstraction, individuals focus on the more concrete, incidental features (Liberman \& Trope, 2008). Given that holding a more structural understanding of discrimination should highlight the societal implications and effects of discrimination, this broader focus could translate into conceptualizing the experience of group disadvantage itself more abstractly. Thus, considering the broader societal and cultural factors that contribute to intergroup inequality may lead stigmatized group members to construe their experiences with discrimination at a more abstract level and, in turn, more-readily focus on shared aspects of group disadvantage that do not vary across types of discrimination (e.g., societal devaluation). Conversely, interpersonal forms of discrimination may highlight more idiosyncratic differences between 
stigmatized groups' discrimination experiences (e.g., differing stereotype content or perpetrators of bias), which may not facilitate and could even hinder intergroup solidarity. The present research tests these possibilities and examines whether considering discrimination facing one's own group to stem from structural or interpersonal forces may influence the perceived pervasiveness of discrimination and/or one's construal level, which in turn, affect intra-minority solidarity.

\section{Overview of Studies}

The present research provides a quantitative empirical examination of whether holding more structural or interpersonal understandings of discrimination against one's own group facilitates solidarity and support for coalescing with members of other stigmatized groups. In Study 1, analyzing nationally-representative data sets, we examine whether Hispanic Americans, Black Americans, and White women who hold more structural (vs. interpersonal) views of the discrimination faced by their groups (racism and sexism, respectively) express greater attention to issues and support for political movements affecting another stigmatized group. We also explore whether beliefs that ingroup discrimination is structurally- or interpersonally-driven relates to coalitional attitudes and support for other stigmatized groups in correlational (Study 2) and experimental studies (Studies 3-4). Study 4 also provides an initial test for mechanisms underlying support for intra-minority coalitions. Overall, structural, relative to interpersonal, understandings of ingroup discrimination are expected to facilitate coalitional attitudes and expressed solidarity with other stigmatized groups; we will test whether this may occur due to greater perceived pervasiveness of discrimination and/or 
heightened psychological abstraction occurring when considering structural aspects of discrimination.

\section{Study 1}

Study 1 provides an initial test for a link between structural (vs. interpersonal) understandings of discrimination and intergroup solidarity. Across three nationally-representative samples, we examine how beliefs about discrimination as interpersonally- or structurally-driven relate to Hispanics' (Study 1a), Black Americans' (Study 1b), and White women's (Study 1c) expressed solidarity with a racial minority outgroup (support for an activist organization and attention to political issues seen as primarily affecting another stigmatized group). We predicted that individuals holding more structural (vs. interpersonal) conceptions of their own group's discrimination would express greater support for another stigmatized group and engagement with issues affecting other stigmatized groups.

\section{Method}

\section{Data}

We conducted analyses on data from three national surveys assessing Americans' racial and political attitudes (S1a: 2015 CNN/Kaiser Family Foundation Survey of Americans on Race, $N=1951$; S1b: Pew Research Center 2016 Racial Attitudes in America Survey, $N=3769$; S1c: Pew Research Center December 2017 Political Survey, $N=1503)$. All surveys utilized randomdigit-dialing and Studies 1a and 1b oversampled Black and Hispanic Americans. ${ }^{1}$

Our primary outcome variable in Study 1a was support for Black Lives Matter (BLM), so we conducted subpopulation analyses on the most well-represented non-Black racial minority group in the survey-Hispanic respondents who were not Black ( $n=429 ; 52.45 \%$ women, median age 30-49 years old). In Study 1b, the item assessing beliefs about discrimination 
explicitly focused on anti-Black racism, so we conducted subpopulation analyses on Black respondents who were not Hispanic $\left(n=998 ; 51.20 \%\right.$ women, $\left.M_{\text {age }}=50.83, S D_{\text {age }}=17.37\right)$. Study 1c examined White women respondents' attitudes toward racial issues $\left(n=417 ; M_{\mathrm{age}}=56.42\right.$, $\left.S D_{\text {age }}=18.00\right)$. These sample sizes have $80 \%$ power to detect small effects $\left(f^{2} \mathrm{~s}=.02, .01\right.$, and .02 , respectively).

\section{Measures}

Lay Theories of Discrimination. In Study $1 \mathrm{a}$ and $1 \mathrm{~b}$, respondents indicated which kind of racial discrimination they perceived to be a greater problem: discrimination built into laws, society, and institutions (structural discrimination; coded as 1) or discrimination stemming from individuals' prejudices (interpersonal discrimination; coded as 0). The item in Study 1a referred to racial discrimination, generally, whereas the item in Study $1 b$ focused on anti-Black discrimination, specifically. On average, both Hispanic (S1a) and Black respondents (S1b) were split in the degree to which they expressed interpersonal or structural beliefs (S1a: $M=0.47$, $95 \% \mathrm{CI}[0.42,0.52], S D=0.50 ; \mathrm{S} 1 \mathrm{~b}: M=0.44,95 \% \mathrm{CI}[0.41,0.48], S D=0.50)$.

In Study 1c, White women indicated whether they believed that recent examples of gender discrimination (i.e., sexual harassment allegations in the media and politics, see U. S. Equal Employment Opportunity Commission, n.d.) are better characterized as individuals' misconduct (an interpersonal view; coded as 0 ) or as widespread societal problems (a structural view; coded as 1). Perhaps due to the heightened salience of harassment allegations in an era of \#MeToo, on average, White women reported more structural beliefs about these examples of gender discrimination $(M=0.83,95 \% \mathrm{CI}[0.80,0.87], S D=0.37)$.

Support for Stigmatized Outgroups. To assess support for stigmatized outgroups, Hispanic respondents in Study la were asked if they considered themselves supporters of the 
Black Lives Matter (BLM) movement $(1=Y e s, 0=N o)$. On average, $36 \%$ of Hispanic respondents supported the movement.

In Study 1b, Black respondents indicated the frequency with which they spoke about various issues with family and friends (e.g., the economy). Of particular interest was respondents' reported frequency (1=Never, 4=Often $)$ of discussing an issue often associated with Hispanic Americans_-immigration (see Craig et al., 2020; Pérez, 2010). This item provides an index of engagement on an issue seen as affecting another minority group. On average, Black respondents reported discussing immigration somewhere between sometimes and rarely $(M=2.47,95 \% \mathrm{CI}[2.40,2.53], S D=1.04)$.

In Study 1c, White women indicated the extent to which they believed the amount of attention paid to racial issues was sufficient, too much, or not enough (1=Too much attention, $2=$ About the right amount of attention, $3=$ Too little attention). On average, White women reported that attention paid to racial issues was currently slightly inadequate $(M=2.16,95 \% \mathrm{CI}$ $[2.07,2.24], S D=0.86)$.

\section{Results}

As shown in Figure 1, Hispanic respondents (S1a) with more structural views of racism expressed greater support for Black Lives Matter, than those with a more interpersonal understanding $(\Phi=0.14, t=2.50, p=.012$, Odds Ratio $(O R)=1.81,95 \% \mathrm{CI}[1.14,2.88])$. Similarly, Black respondents (S1b) who indicated a more structural (vs. interpersonal) understanding of anti-Black inequality also reported greater discussion of immigration, an issue seen as impactful for Hispanics in particular, $b=0.25(S E=0.07), t=3.60, p<.001, r=.12,95 \% \mathrm{CI}[.09, .15]$. Finally, White women (S1c) who indicated a more structural (vs. interpersonal) understanding of gender discrimination were more likely to report that racial issues were not discussed enough, 
$b=0.51(S E=0.11), t=4.47, p<.001, r=.22,95 \% \mathrm{CI}[.17, .27]$. These results are consistent if controlling for respondents' political ideology and demographic characteristics (i.e., age, household income, and gender [in S1a, S1b]), [S1a: $b=0.65(S E=0.26), t=2.52, p=.012, O R=1.92$, $95 \% \mathrm{CI}[1.15,3.19] ;$ S1b: $b=0.25(\mathrm{SE}=0.07), t=3.53, p<.001, r_{\text {partial }}=.12,95 \% \mathrm{CI}[.09, .16]$; S1c: $b=$ $\left.0.40(S E=0.12), t=3.27, p=.001, r_{\text {partial }}=.20,95 \% \mathrm{CI}[.15, .25]\right]$.

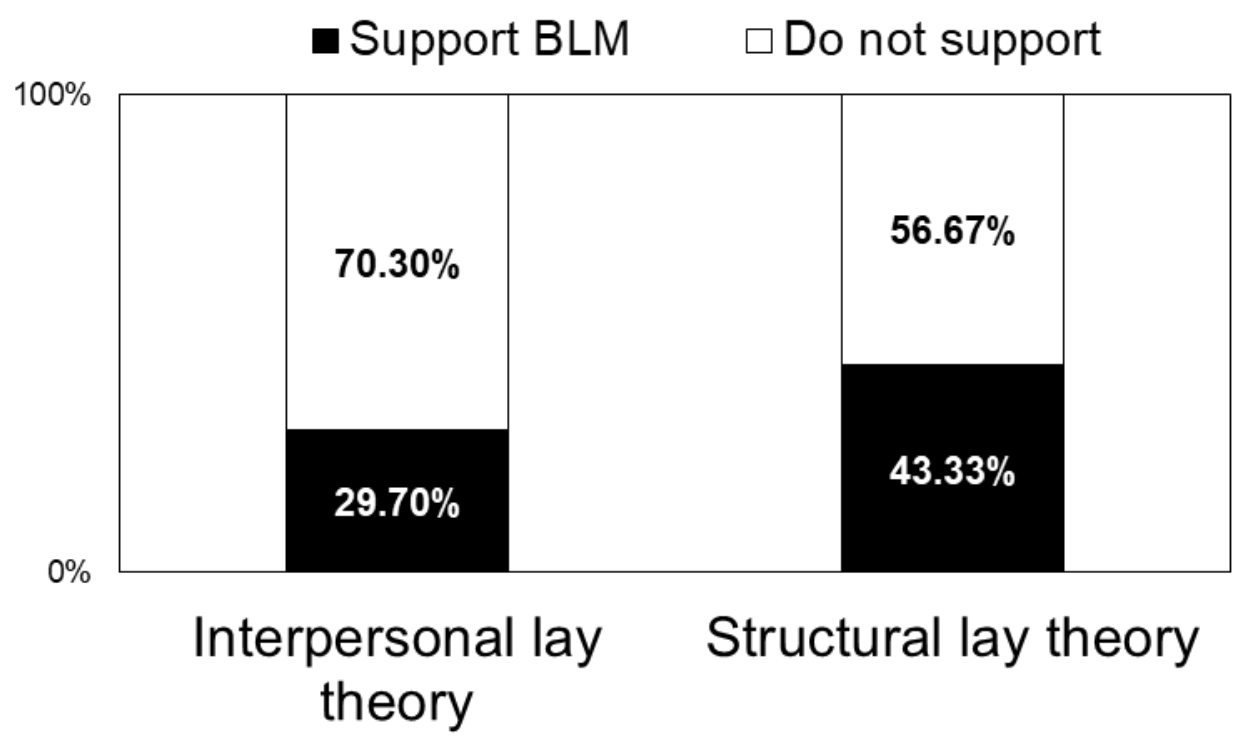

Figure 1. Percentage of Hispanic respondents supporting Black Lives Matter (BLM), by lay theory of racism.

\section{Discussion}

Taken together, Study 1 reveals links between Hispanics' and Blacks' beliefs about racism and expressed solidarity with one another as well as an association between White women's beliefs about gender discrimination and perceptions that insufficient attention is paid to racial issues. This study provides evidence that a structural understanding of the discrimination impacting one's own group may facilitate solidarity across stigmatized groups, however several 
aspects warrant further examination. For example, while a strength of analyzing existing national datasets is the representativeness of the samples and increased confidence in the generalizability of the observed associations, secondary data analysis necessarily involves a lack of control over which questions were asked. Nevertheless, the consistency of results across several outcome measures that triangulate around support for activism and engagement with issues affecting stigmatized outgroups attests to the robustness of the associations.

\section{Study 2}

Study 2 examined how White women's and LGBTQ individuals' lay beliefs about ingroup discrimination relate to expressed support of other stigmatized groups and desires to form coalitions. We conducted surveys assessing beliefs about what drives discrimination against one's ingroup (structural or interpersonal factors) as well as perceived similarity and support for solidarity with members of other stigmatized groups. Consistent with the results of Study 1, we hypothesized that the degree to which White women perceived sexism (Study 2a) and LGBTQ individuals perceive LGBTQ discrimination (Study 2b) to be driven by structural forces would predict perceiving different types of discrimination (e.g., sexism, racism) as linked, expressing support for collectively acting with other stigmatized groups, and support for action and causes benefitting another stigmatized group.

\section{Method}

\section{Participants}

We collected data from White women $\left(\mathrm{S} 2 \mathrm{a}: N=64 ; M_{\mathrm{age}}=27.28, S D_{\mathrm{age}}=11.70\right)$ and nonBlack members of the LGBTQ community $\left(\mathrm{S} 2 \mathrm{~b}: N=142 ; M_{\mathrm{age}}=37.59, S D_{\mathrm{age}}=14.11 ; 27\right.$ women, 90 men, 25 other; 7 Asian Americans, 27 Hispanic Americans, 88 White Americans, 20 other) in public areas around New York City. Analysis did not begin until data collection had completed 
(see the methodology file for additional context on these studies). The samples have $80 \%$ power to detect small-to-medium-sized effects (S2a: $f^{2}=.13, \mathrm{~S} 2 \mathrm{~b}: f^{2}=.06$ ).

\section{Materials and measures}

Lay Theories of Discrimination. Participants indicated their lay beliefs about ingroup discrimination (S2a: sexism, S2b: anti-LGBTQ discrimination; adapted from O'Brien et al., 2009; Rucker et al., 2020; see the methodology file for wording of all questions). Participants reported their agreement ( $1=$ Strongly disagree, $7=$ Strongly agree $)$ with statements such as "Most of the discrimination that [women | LGBTQ individuals] face stems from policies that, even if unintentional, disproportionately disadvantage [women | LGBTQ people]" and "[Sexism | Heterosexism] is primarily caused by [sexist $\mid$ biased] individuals who have negative attitudes toward [women | LGBTQ individuals]." Separate indices were created by averaging items assessing perceptions that ingroup discrimination is driven by structural factors (2-item structural-beliefs index; S2a: $r=.36$, S2b: $r=.71, p s<.004$ ) or by interpersonal bias (2-item interpersonal-beliefs index; S2a: $r=.60, \mathrm{~S} 2 \mathrm{~b}: r=.52, p s<.001)$. These indices were uncorrelated with one another in Study 2a $(r=.10, p=.443)$ and moderately correlated in Study $2 \mathrm{~b}(r=.30$, $p<.001)$.

Coalitional Attitudes. To assess coalitional attitudes, participants completed items assessing their perceived similarity with and desire to work together with other oppressed groups (adapted from the Oppressed Minority Subscale, see Sellers et al., 1997). Questions focused on a self-identified group that participants reported belonging to that has faced discrimination (S2a) or on LGBTQ individuals (2b). For example, participants indicated their agreement (1=Strongly disagree, $7=$ Strongly agree) to a series of statements, including "The discrimination [my group | LGBTQ individuals] has experienced is similar to that of other minority groups," and "People 
from [my group | LGBTQ individuals] should treat other oppressed people as allies." Items were averaged to create an index of coalitional attitudes (S2a: 9-items, $\alpha=.85 ; 2 \mathrm{~b}$ : 5 -items, $\alpha=.80$ ) with higher scores indicating greater perceptions of similarity across types of discrimination and reported interest in forming coalitions.

Support for Other Stigmatized Groups. For Study 2a, participants reported the likelihood (1=Extremely unlikely, $7=$ Extremely likely) that they would attend future protests to support a variety of groups, including the ingroup (i.e., women), a stigmatized outgroup (i.e., racial minorities), and other stigmatized social groups (i.e., undocumented immigrants, religious minorities, the LGBT community). ${ }^{2}$ For Study $2 b$, participants reported their attitudes towards movements and policies seeking to support Black Americans (5-items: e.g., support for the Black Lives Matter movement, 1=Extremely oppose, $7=$ Extremely support, $\alpha=.84)$. Participants were also given the opportunity to sign change.org petitions by taking a picture of a QR-code (see methodology file). Two petitions were offered, one indicating support for reparations for Black Americans (stigmatized outgroup-focused petition) and the other indicating support for the LGBTQ-focused Equality Act (ingroup-focused petition). Because very few participants signed only the race-petition $(n=4)$, we examine responses of participants who signed neither petition $(n=61)$, those who only signed the LGBTQ petition $(n=24)$, and those who signed both $(n=52)$.

\section{Procedure}

Participants were approached by research assistants asked to complete a survey in exchange for candy (S2a) or a bottle of water (S2b). Upon providing informed consent, participants reported their beliefs about what drives ingroup discrimination (S2a: sexism, S2b: LGBTQ discrimination), their coalitional attitudes, intentions to attend future protests (S2a), support for policies benefitting Black Americans (S2b), and demographic information (e.g., 
gender, race) on pen-and-paper surveys. Last, participants in S2b were given the opportunity to sign the petitions (race-petition, LGBTQ-petition; order counter-balanced). After returning the survey, participants received debriefing information and were compensated.

\section{Results}

Descriptive statistics and zero-order correlations for variables are presented in Tables 1a and $1 \mathrm{~b}$. To examine the unique links between the outcomes and beliefs about ingroup discrimination being driven by structural or interpersonal factors, we conducted multiple regression analyses in which interpersonal beliefs and structural beliefs are simultaneously included as predictors. Thus, for results reported in Study 2, the relationships between structural discrimination beliefs and the outcome measures are adjusting for the influence of interpersonal beliefs (and vice versa).

\section{Coalitional Attitudes}

Consistent with the hypothesis that structural understandings of ingroup discrimination facilitate coalitional attitudes, participants' beliefs that their group's discrimination is driven by structural forces (e.g., policies and institutional practices) predicted the expression of coalitional attitudes (S2a: $b=.56(S E=0.11), t=5.16, p<.001, r_{\text {partial }}=.56,95 \% \mathrm{CI}[.36, .71]$; S2b:

$\left.b=.19(S E=0.06), t=3.19, p=.002, r_{\text {partial }}=.26,95 \% \mathrm{CI}[.10, .41]\right)$. In contrast, participants' beliefs that ingroup discrimination is driven by individuals' negative attitudes did not significantly predict coalitional attitudes (S2a: $b=-.12(S E=0.07), t=1.75, p=.085, r_{\text {partial }}=-.22,95 \% \mathrm{CI}[-.45, .03]$; S2b: $\left.b=-.01(S E=0.06), t=0.13, p=.898, r_{\text {partial }}=-.01,95 \% \mathrm{CI}[-.18, .15]\right)$.

\section{Support for Stigmatized Outgroups}

Similarly, participants' beliefs that ingroup discrimination is driven by structural forces also positively predicted intentions to attend protests to support other stigmatized groups (S2a: 
e.g., racial minorities, $\left.b=.91(S E=0.21), t=4.31, p<.001, r_{\text {partial }}=.49,95 \% \mathrm{CI}[.27, .66]\right)$,

undocumented immigrants, $\left.\left.b=1.07(S E=0.21), t=5.01, p<.001, r_{\text {partial }}=.54,95 \% \mathrm{CI}[.34, .69]\right)\right)$, and support for policies benefitting another stigmatized group (e.g., reparations for Black Americans, S2b: $\left.b=.48(S E=0.06), t=7.51, p<.001, r_{\text {partial }}=.54,95 \% \mathrm{CI}[.41, .65]\right)$. In contrast, beliefs that ingroup disadvantage is driven by interpersonal discrimination were either statistically unrelated or negatively related to intentions to protest for other stigmatized groups and support for policies benefitting a stigmatized outgroup (S2a: racial minorities, $b=-.15(S E=0.13), t=1.15, p=.253$, $\left.r_{\text {partial }}=-.15,95 \% \mathrm{CI}[-.38, .11]\right)$, undocumented immigrants, $b=-0.27(S E=0.13), t=2.00, p=.050$, $r_{\text {partial }}=-.25,95 \% \mathrm{CI}[-.47, .00], \mathrm{S} 2 \mathrm{~b}: b=-.20(S E=0.07), t=3.04, p=.003, r_{\text {partial }}=-.25,95 \% \mathrm{CI}[-.40,-$ $.09]$.

Finally, examining the behavioral measure from Study $2 b$, we conducted multinomial logistic regression, regressing the likelihoods of signing both the LGBTQ and Black-reparations petitions, of signing the LGBTQ petition only, and of signing neither petition on participants' beliefs about what drives their own group's discrimination. Results revealed that holding a structural understanding of ingroup discrimination predicts greater likelihood of signing both petitions (i.e., LGBTQ Equality Act and Black-reparations petitions), compared with signing the LGBTQ petition only, $b=0.44(S E=.20)$, Wald $\chi^{2}=5.00, p=.025, O R=1.56,95 \% \mathrm{CI}[1.06,2.30]$, or (marginally) opting to sign neither petition, $b=0.31\left(S E=.17\right.$ ), Wald $\chi^{2}=3.45, p=.063, O R=1.37$, $95 \% \mathrm{CI}[0.98,1.90]$. In contrast, beliefs that interpersonal bias drives ingroup disadvantages did not reliably relate to participants' likelihood of signing both petitions, compared with signing the LGBTQ petition only, $b=-0.09(S E=.20)$, Wald $\chi^{2}=0.19, p=.662, O R=0.92,95 \% \mathrm{CI}[0.62,1.36]$, or opting to sign neither, $b=0.02(S E=.15)$, Wald $\chi^{2}=0.01, p=.908, O R=1.02,95 \% \mathrm{CI}[0.76,1.37]$. Overall, the more that LGBTQ individuals held a structural view of their own group's 
discrimination, the more likely they were to sign petitions for both the ingroup and a stigmatized outgroup, compared with only signing a petition supporting the ingroup or declining to sign at all; concurrently, no relationship emerged between beliefs about interpersonal discrimination and petition-signing behavior. 
Table 1a

Descriptive statistics and zero-order correlations for White women's support of protesting for different social groups (Study 2 a).

Variables

$$
M
$$

4

5

Lay theories and coalitional attitudes

1. Structural understanding of sexism

$5.66 \quad 1.00$

10

2. Interpersonal understanding of

$3.84 \quad 1.58$

.10

$.54^{* * *}$

$.38^{* *}$

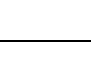

$\begin{array}{lllll}6 & 7 & 8 & 9 & 10\end{array}$

11 sexism
3. Coalitional attitudes

$5.87 \quad 0.98$

$-\quad-.14$

.01

$.46^{* * *}$

$.47^{* * *}$

$.52^{* * *}$

$.37^{* *} \quad .52^{* * *} \quad .28^{*}$

Likelihood of protesting for the following groups

4. Women

5. The LGBTQ community

6. Racial minorities

7. Undocumented immigrants

8. Disabled people

9. Religious minorities

10. Low-income White people

11. Overweight people
$6.28 \quad 1.49$

$5.83 \quad 1.87$

$5.67 \quad 1.86$

$5.36 \quad 1.98$

$5.25 \quad 1.93$

$5.09 \quad 2.07$

$3.84 \quad 1.97$

3.192 .00 $-\quad .81^{* * *} \quad .79^{* * *} \quad .67^{* * *} \quad .65^{* * *} \quad .66^{* * *} \quad .40^{* *} \quad .35^{* *}$

$-\quad .84^{* * *} \quad .78^{* * *} \quad .73^{* * *} \quad .83^{* * *} \quad .50^{* * *} .46^{* * *}$

$-\quad .80^{* * *} \quad .70^{* * *} \quad .81^{* * *} \quad .48^{* * *} \quad .39^{* *}$

$-\quad .69^{* * *} \quad .72^{* * *} \quad .56^{* * *} \quad .31^{*}$

$-\quad .66^{* * *} .63^{* * *} .54^{* * *}$

$-\quad .51^{* * *} .43^{* *}$

Note. ${ }^{\dagger} p<.10 ;{ }^{*} p<.05 ;{ }^{* *} p<.01 ;{ }^{* * *} p<.001$ 
Table $1 \mathrm{~b}$

Descriptive statistics and zero-order correlations for non-Black LGBTQ individuals'support of Black Americans (Study 2b).

Variables

$M$

$S$

1. Structural understanding of LGBTQ discrimination

5.54

$S D$

12

3

4

2. Interpersonal understanding of LGBTQ discrimination

5.35

1.38

$-$

$.30^{* * *}$

$.27^{* * *}$

$.49^{* * *}$

3. Coalitional attitudes

6.04

1.34

$-$

.07

$-.06$

4. Support for policies benefitting Black Americans

5.87

0.97

$-\quad .39^{* * *}$

Note. ${ }^{* * *} p<.001$ 


\section{Discussion}

Consistent with the results of Study 1 and prior qualitative work (Curtin et al., 2016), Study 2 suggests that the extent to which White women and LGBTQ individuals perceived structural factors to drive ingroup discrimination was associated with greater expressed coalitional attitudes and support for other stigmatized groups. Because we created the measures utilized in Study 2, they rigorously assess the concepts of interest. These results provide corroborating support for the idea that beliefs that disadvantages faced by one's own group are driven by structural discrimination predict perceived similarity and support (including with a behavioral measure) for other stigmatized groups. However, these results (as well as those from Study 1) still warrant the typical caveats of correlational research. As such, the remaining studies will test for causality by including experimental manipulations of lay theories of discrimination.

\section{Study 3}

Across a variety of social groups and outcome measures, Studies 1 and 2 revealed consistent links between structural beliefs about ingroup discrimination and expressed solidarity and support for coalescing with other stigmatized groups. Study 3 tests for causality and, specifically, whether highlighting structural (vs. interpersonal) aspects of one's own group's disadvantage actually leads to greater support for other stigmatized groups. In Study 3, White women viewed an infographic alleging that either structural or interpersonal discrimination primarily drive sexism and then reported their coalitional attitudes and expressed solidarity with racial minorities. We predicted that making structural (vs. interpersonal) factors contributing to sexism salient among White women would lead to greater coalitional attitudes and support for efforts to reduce racial inequality.

\section{Method}




\section{Participants}

White women (S3a: $N=95 ; \mathrm{S} 3 \mathrm{~b}: N=172)$ were recruited from MTurk.com in exchange for $\$ 0.50$. All participants (S3a: $\left.M_{\mathrm{age}}=40.18, S D_{\mathrm{age}}=13.32 ; \mathrm{S} 3 \mathrm{~b}: M_{\mathrm{age}}=40.87, S D_{\mathrm{age}}=11.69\right)$ were United States citizens. For Study 3a, we aimed for a minimum of 40 participants in each between-subjects cell. For Study 3b, based on a power analysis using the results of Study $3 a$, we sought to recruit a minimum of 168 participants. Data collection was completed before any data analysis. These sample sizes have $80 \%$ power to detect medium effects $(d \mathrm{~s}=0.58,0.43$ in S3a and $\mathrm{S} 3 \mathrm{~b}$, respectively).

\section{Materials and Measures}

Lay Theories of Sexism Manipulation. Participants were randomly-assigned to view a brief infographic (see methodology file) that alleged that sexism was driven by either a) structural factors, or b) interpersonally-expressed bias. For example, participants read that the gender pay gap was driven by institutional policies and practices (structural sexism condition) or by individuals' negative attitudes and stereotypes (interpersonal sexism condition). Thus, all participants read about discrimination affecting the ingroup (sexism), but whether structural or interpersonal forms of discrimination were described varied across experimental condition.

As a manipulation check, we assessed lay theories of sexism as in Study 2a (1=Strongly disagree, 7=Strongly agree; O’Brien et al., 2009; Rucker et al., 2020) and created separate indices of beliefs that structural factors drive sexism (S3a: $r=.80, \mathrm{~S} 3 \mathrm{~b}: r=.79, p \mathrm{~s}<.001)$ and that interpersonal factors drive sexism $(\mathrm{S} 3 \mathrm{a}: r=.62, \mathrm{~S} 3 \mathrm{~b}: r=.63, p \mathrm{~s}<.001)$. These indices were moderately positively correlated with one another (S3a: $r=.45, \mathrm{~S} 3 \mathrm{~b}: r=.28, p \mathrm{~s}<.001)$.

Coalitional Attitudes. As in Study 2, participants reported (1=Strongly disagree, 7=Strongly agree) perceived similarity with and desire to work together with other oppressed 
groups (9-items, S3a: $\alpha=.94$, S3b: $\alpha=.91$; Sellers et al., 1997). In Study 3, however, the items explicitly focused on women and experiences with sexism (e.g., "Women should treat other oppressed people as allies"). Again, higher scores indicate greater perceptions that women have similar experiences and should work together with other oppressed groups.

Support for Racial Minorities. In Study 3b, participants were also asked to report their a) willingness to sign a petition to support reducing U.S. racial inequality (1=Extremely unwilling, 7=Extremely willing), b) likelihood of attending a protest to support racial minorities $(1=$ Extremely unlikely, $7=$ Extremely likely $)$, and c $)$ support of the Black Lives Matter movement $(1=$ Strongly oppose, $7=$ Strongly support $)$. Because the anchor labels varied across items, we standardized the items prior to creating an index with higher values indicating greater support for collective action to reduce racial inequality (3-items; $\alpha=.85$ ).

\section{Procedure}

Participants first provided informed consent and completed an initial set of demographic questions (e.g., race, gender). They were then randomly-assigned to view one of the infographics (about structural sexism or interpersonal sexism) providing the experimental manipulation. Participants reported their coalitional attitudes as well as support for collective action to support racial minorities (S3b only). ${ }^{3}$ Last, participants indicated their lay theories of sexism (manipulation check), and completed additional demographic questions (e.g., age), prior to debriefing.

\section{Results}

The final samples included 95 participants (47 structural sexism condition, 48 interpersonal sexism condition) in Study 3a and 172 participants (91 structural sexism condition, 81 interpersonal sexism condition) in Study 3 b. Given heteroscedasticity of variances for 
outcomes in Study 3a, degrees of freedom are adjusted using the Welch-Satterthwaite method. Missing data in Study $3 b$ leads the degrees of freedom to vary across analyses.

\section{Manipulation Check}

As shown in Table 2, beliefs about structural sexism were significantly affected by the experimental manipulation such that White women exposed to information alleging that structural discrimination drives sexism were more likely to report a structural understanding of sexism than participants exposed to information about interpersonal sexism, $[\mathrm{S} 3 \mathrm{a}: t(66.93)=2.12$, $p=.038, d=0.45, \mathrm{~S} 3 \mathrm{~b}: t(164)=3.16, p=.002, d=0.49]$. Beliefs about interpersonal factors contributing to sexism, however, did not significantly differ by experimental prime [S3a: $t(75.87)=1.46, p=.149, \mathrm{~S} 3 \mathrm{~b}: t(164)=1.26, p=.210]$. We speculate that may be because individuals tend to more-readily acknowledge interpersonal factors contributing to inequalities than structural factors (see Blodorn et al., 2012; Bobo, 2001; Bonilla-Silva, 2015; Nelson et al., 2013; Unzueta \& Lowery, 2008). Thus, information about interpersonal factors driving sexism may not depart from individuals' typical assumptions. 
Table 2

Study 3: Descriptive statistics by experimental condition.

\begin{tabular}{llccc} 
& \multicolumn{2}{c}{ Interpersonal sexism condition } & \multicolumn{2}{c}{ Structural sexism condition } \\
\cline { 2 - 6 } & $M(S D)$ & $95 \%$ CI & $M(S D)$ & $95 \%$ CI \\
\hline Study $3 a$ & & & & \\
Structural lay theory of sexism & $4.69(1.95)$ & {$[4.23,5.15]$} & $5.38(1.05)$ & {$[4.93,5.83]$} \\
Interpersonal lay theory of sexism & $4.69(1.61)$ & {$[4.29,5.09]$} & $5.11(1.07)$ & {$[4.71,5.50]$} \\
Coalitional attitudes & $4.33(1.67)$ & {$[3.91,4.75]$} & $5.05(1.14)$ & {$[4.63,5.46]$} \\
Study $3 b$ & & & & \\
Structural lay theory of sexism & $4.64(1.49)$ & {$[4.31,4.97]$} & $5.35(1.43)$ & {$[5.05,5.66]$} \\
Interpersonal lay theory of sexism & $4.84(1.38)$ & {$[4.54,5.14]$} & $5.10(1.32)$ & {$[4.82,5.38]$} \\
Coalitional attitudes & $4.71(1.16)$ & {$[4.44,4.97]$} & $5.06(1.24)$ & {$[4.81,5.31]$} \\
Support for racial minorities & $-0.16(0.86)$ & {$[-0.35,0.03]$} & $0.14(0.87)$ & {$[-0.04,0.32]$} \\
\hline
\end{tabular}

Note: The items assessing support for racial minorities were standardized prior to creating the index.

\section{Coalitional Attitudes}

Consistent with predictions that structural lay theories of ingroup discrimination facilitate coalitional attitudes, White women exposed to the structural sexism infographic expressed greater perceived similarity of discrimination experiences and support for working together with other oppressed groups, compared with those in the interpersonal sexism condition [S3a:

$t(77.28)=2.39, p=.019, d=0.50, \mathrm{~S} 3 \mathrm{~b}: t(170)=1.90, p=.059, d=0.29]$.

\section{Support for Racial Minorities}

Also aligned with predictions, White women exposed to information about structural sexism reported greater support for collective action to reduce racial inequality (i.e., a different form of inequality than that experienced by participants), compared with participants in the interpersonal sexism condition, $t(169)=2.24, p=.027, d=0.34$. 


\section{Discussion}

Consistent with the correlational findings from Studies 1-2, Study 3 provides causal evidence that making structural aspects of one's own group's discrimination salient can facilitate coalitional attitudes and support for action to reduce inequality faced by another stigmatized group. However, the design of these experiments did not include a way of assessing individuals' baseline lay beliefs about sexism. Prior research (e.g., Blodorn et al., 2012) and the pattern of results in which interpersonal beliefs about sexism did not vary by experimental condition are consistent with the possibility that White women may tend to view sexism as stemming from interpersonal sexism by default, but Study 4 will include a control condition in which sexism is not made salient to test this. Additionally, while Study 3 provides evidence of an effect of lay theories of sexism on coalitional attitudes, why this effect may occur is still untested. Study 4 will provide an initial test for psychological mechanism.

\section{Study 4}

Study 4 was a preregistered experiment that had a similar design to Study 3 . White women were randomly assigned to view an infographic whose content was varied to provide the experimental manipulation. Again, two of the conditions highlighted gender inequality and alleged that it was either driven by interpersonal factors (interpersonal condition) or by structural factors (structural condition). By including a new third control condition, in which no information about discrimination was provided, Study 4 provides insight into whether the effects of Study 3 may have been driven by salient structural discrimination or salient interpersonal discrimination (or if both may have contributed).

Finally, Study 4 included measures of psychological abstraction and perceived pervasiveness of sexism, allowing for an initial test of two possible underlying mechanisms. As 
noted in the Introduction, psychological abstraction and perceived pervasiveness are good candidates to consider for why highlighting the broader societal and cultural factors that contribute to discrimination may lead stigmatized group members to perceive discrimination experiences as related and express support for coalescing with other stigmatized groups. Given that societal structures and institutions are represented at a more abstract level than are individuals (e.g., institutions can be composed of individuals, but the reverse is not true; see Liberman \& Trope, 2008; Trope \& Liberman, 2010), considering structural forms of discrimination may lead individuals to construe their discrimination experiences at a more abstract level and, in turn, they may more-readily focus on shared aspects of group disadvantage that do not vary across social groups. Conversely, considering interpersonal forms of discrimination may lead to a lower level of abstraction and a focus on the concrete details of one's discrimination experiences which may not be similar across types of stigma (e.g., idiosyncratic stereotypic content). Additionally, the results of Study 3 suggested that perceptions of interpersonal sexism do not decrease if structural aspects of discrimination are made salient. As a result, enhancing perceptions of structural sexism may serve to increase perceptions that sexism is a problem and individuals may seek out coalitions to address this perceived larger issue. To test for this possibility, Study 4 assessed the perceived pervasiveness of sexism.

Consistent with the results of Study 3, we expected that the infographic priming structural conceptions of gender discrimination would elicit greater coalitional attitudes and support for racial minorities, compared with the interpersonal sexism condition or the control condition. We also predicted that the interpersonal sexism condition would lead to less coalitional attitudes and support for racial minorities, compared with the control condition. We were agnostic in terms of our predictions for the mediators (both seemed plausible). If psychological abstraction underlies 
effects, then White women in the structural sexism condition should conceptualize several behaviors relating to collective action meant to reduce inequality in a more abstract manner. For example, White women primed with a structural view of gender discrimination would be more likely to describe the behavior of signing a petition as expressing support for a cause than writing one's name on paper, compared with women provided with interpersonal examples of gender discrimination. If perceived pervasiveness of discrimination drives effects, then considering structural sexism should also increase perceptions that gender inequality is a big, pervasive problem.

\section{Method}

\section{Participants}

White women $\left(N=454 ; M_{\text {age }}=36.26, S D_{\text {age }}=12.80\right)$ were recruited from Prolific.ac in exchange for $\$ 1.32$. As indicated in our preregistration report, we sought to recruit a minimum of 441 participants, based on a power analysis (to achieve $90 \%$ power) using the effect size for the racial solidarity measure in Study 3 b (i.e., $d=.34$ or $f=.17$ ). Thus, this sample size has $80 \%$ power to detect small-to-medium effects $(f=0.15)$.

\section{Materials and Measures}

Lay Theories of Sexism Manipulation. As in Study 3, participants were randomlyassigned to view a brief infographic (see methodology file) and two conditions referred to gender discrimination that was either driven by a) institutional and structural factors (structural sexism condition) or b) interpersonally-expressed bias (interpersonal sexism condition). Additionally, Study 5 includes a third condition that refers to negative societal events, unrelated to gender discrimination (control condition). Specifically, the control condition gave information about automobile accidents driven by sleep disruption following the switch to Daylight Saving Time. 
Again, we assessed lay theories of sexism as in Study 2a (1=Strongly disagree, $7=$ Strongly agree; O’Brien et al., 2009; Rucker et al., 2020) and created separate indices of beliefs that structural factors drive $\operatorname{sexism}(r=.73, p<.001)$ and that interpersonal factors drive $\operatorname{sexism}(r=.60, p<.001)$. These indices were correlated with one another, albeit modestly $(r=.12, p=.013)$.

Perceived Pervasiveness of Sexism. To assess perceptions that sexism is a larger and more pervasive issue, participants indicated their agreement $(1=$ Strongly disagree, $7=$ Strongly agree) that a) sexism is a big problem as well as b) that sexism occurs in rare, isolated situations (reverse-coded). These items were highly correlated $(r=.66, p<.001)$, so we created a composite such that higher numbers indicate greater perceptions that sexism is a pervasive problem.

Psychological Abstraction. To assess psychological abstraction, we adapted the Behavioral Identification Form (BIF; Vallacher \& Wegner, 1989) to measure how participants conceptualize several behaviors related to collective action. In this task, participants are presented with actions and asked to indicate how they would best describe those actions on a scale anchored by two options varying in abstraction. That is, one endpoint of the scale includes a more concrete way of representing the behavior and the other endpoint is a more abstract representation. For example, participants rated their perceptions of protesting $(1=$ Expressing one's values, $7=$ Shouting [reverse-coded] $)$ and forming a coalition $(1=$ Working in a group with other people, $7=$ Acting in solidarity). The more abstract and more concrete phrases used as the endpoints of the items were generated using the original BIF as a guide. Then, we checked against a list of 40,000 words that were independently rated on perceived concreteness (i.e., on a scale of $1=$ abstract to $5=$ concrete; Brysbaert et al., 2014) to test if our more concrete labels indeed included words that were, on average, more concrete. Consistent with expectations, a mixed-effects model predicting perceived concreteness ratings from endpoint label type (1=more 
abstract endpoint, $0=$ more concrete endpoint), with the intercept randomly varying between item revealed that the more concrete endpoint labels included words rated as more concrete and less $\operatorname{abstract}(M=3.06,95 \% \mathrm{CI}[2.72,3.40])$ than the words in the abstract endpoint labels $(M=2.17$, $95 \% \mathrm{CI}[1.80,2.54]), b=0.89(S E=0.24), t(52.83)=3.74, p<.001$. After this confirmation of the validity of the labels, items were recoded and averaged to create an index of psychological abstraction (7-items; $\alpha=.72)$ in which higher scores indicated a more abstract representation of collective action.

Coalitional Attitudes. As in Study 2a, participants reported (1=Strongly disagree, 7=Strongly agree) perceived similarity with and desire to work together with other oppressed groups (9-items, $\alpha=.91$; Sellers et al., 1997). Again, higher scores indicate greater perceptions that women have similar experiences and should work together with other oppressed groups.

Support for Racial Minorities. As in Study 3b, participants reported their willingness to sign a petition to reduce racial inequality, their likelihood of attending a protest to support racial minorities, and their support of the Black Lives Matter movement. Again, we standardized the items prior to creating an index with higher values indicating greater support for collective action to reduce racial inequality (3-items; $\alpha=.85)$.

\section{Procedure}

Participants first provided informed consent and completed an initial set of demographic questions (e.g., race, gender). White women were then filtered into the study and randomlyassigned to view one of the three infographics (structural sexism, interpersonal sexism, control information) providing the experimental manipulation. Participants reported their coalitional attitudes, psychological abstraction, and support for collective action to support racial minorities. Last, participants indicated their perceptions of sexism (including perceived pervasiveness and 
the manipulation check) and completed additional demographic questions (e.g., age), prior to being debriefed and compensated.

\section{Results}

Twenty-two participants passed initial screening into the study, but indicated a non-White identity and nine indicated a non-female gender. After excluding these individuals, the final sample includes 423 White women (136 structural sexism condition, 142 interpersonal sexism condition, 145 control condition). Consistent with our preregistration report, we conducted a series of analyses of variance (ANOVAs), followed by planned contrasts testing the differences among the experimental conditions.

\section{Manipulation Check}

As shown in Table 3, beliefs about structural sexism were significantly affected by the experimental manipulation, $F(2,420)=4.03, p=.018, \eta_{\mathrm{p}}{ }^{2}=.02$. White women in the structural sexism condition were more likely to report a structural understanding of sexism than participants exposed to control information about the negative effects of daylight saving time, $F(1,420)=8.04, p=.005, \eta_{\mathrm{p}}{ }^{2}=.02$. Although the means are in the predicted direction, participants exposed to the structural sexism infographic did not report significantly greater beliefs that structural factors drive gender inequality, compared with participants in the interpersonal sexism condition, $F(1,420)=1.74, p=.188, \eta_{\mathrm{p}}{ }^{2}=.00$. Participants in interpersonal sexism condition similarly did not differ from control participants in their beliefs about structural sexism, $F(1$, $420)=2.33, p=.128, \eta_{\mathrm{p}}{ }^{2}=.01$. 
Table 3

Study 4: Descriptive statistics by experimental condition.

\begin{tabular}{|c|c|c|c|c|c|c|}
\hline & \multicolumn{2}{|c|}{$\begin{array}{l}\text { Interpersonal sexism } \\
\text { condition }\end{array}$} & \multicolumn{2}{|c|}{$\begin{array}{l}\text { Structural sexism } \\
\text { condition }\end{array}$} & \multicolumn{2}{|c|}{ Control condition } \\
\hline & $M(S D)$ & $95 \% \mathrm{CI}$ & $M(S D)$ & $95 \% \mathrm{CI}$ & $M(S D)$ & $95 \% \mathrm{CI}$ \\
\hline Structural beliefs about sexism & $\begin{array}{l}5.01^{\mathrm{a}, \mathrm{b}} \\
(1.47)\end{array}$ & $\begin{array}{c}4.76, \\
5.26]\end{array}$ & $\begin{array}{l}5.25^{\mathrm{a}} \\
(1.34)\end{array}$ & $\begin{array}{l}5.00 \\
5.51]\end{array}$ & $\begin{array}{l}4.74^{\mathrm{b}} \\
(1.70)\end{array}$ & $\begin{array}{l}4.49, \\
4.99]\end{array}$ \\
\hline $\begin{array}{l}\text { Interpersonal beliefs about } \\
\text { sexism }\end{array}$ & $\begin{array}{l}4.68^{\mathrm{a}, \mathrm{b}} \\
(1.47)\end{array}$ & $\begin{array}{l}{[4.44,} \\
4.93]\end{array}$ & $\begin{array}{l}4.35^{\mathrm{a}} \\
(1.47)\end{array}$ & $\begin{array}{l}{[4.11} \\
4.60]\end{array}$ & $\begin{array}{l}4.70^{\mathrm{b}} \\
(1.45)\end{array}$ & $\begin{array}{l}{[4.46,} \\
4.94]\end{array}$ \\
\hline $\begin{array}{l}\text { Perceived pervasiveness of } \\
\text { sexism }\end{array}$ & $\begin{array}{l}5.55^{\mathrm{a}, \mathrm{b}} \\
(1.56)\end{array}$ & $\begin{array}{l}{[5.29} \\
5.81]\end{array}$ & $\begin{array}{l}5.75^{\mathrm{a}} \\
(1.37)\end{array}$ & $\begin{array}{l}{[5.49} \\
6.02]\end{array}$ & $\begin{array}{c}5.39^{\mathrm{b}} \\
(1.70)\end{array}$ & $\begin{array}{l}{[5.14} \\
5.64]\end{array}$ \\
\hline Psychological abstraction & $\begin{array}{l}4.44^{\mathrm{a}} \\
(1.32)\end{array}$ & $\begin{array}{l}{[4.24} \\
4.63]\end{array}$ & $\begin{array}{l}4.81^{\mathrm{b}} \\
(1.05)\end{array}$ & $\begin{array}{l}{[4.61} \\
5.01]\end{array}$ & $\begin{array}{l}4.65^{\mathrm{a}, \mathrm{b}} \\
(1.13)\end{array}$ & $\begin{array}{l}{[4.46} \\
4.84]\end{array}$ \\
\hline Coalitional attitudes & $\begin{array}{l}5.21^{\mathrm{a}, \mathrm{b}} \\
(1.16)\end{array}$ & $\begin{array}{l}{[5.01} \\
5.40]\end{array}$ & $\begin{array}{l}5.34^{\mathrm{a}} \\
(1.15)\end{array}$ & $\begin{array}{l}{[5.14} \\
5.54]\end{array}$ & $\begin{array}{l}5.04^{\mathrm{b}} \\
(1.26)\end{array}$ & $\begin{array}{c}{[4.84} \\
5.23]\end{array}$ \\
\hline Support for racial minorities & $\begin{array}{l}0.01^{\mathrm{a}} \\
(0.86)\end{array}$ & $\begin{array}{c}{[-0.14} \\
0.15]\end{array}$ & $\begin{array}{l}0.06^{\mathrm{a}} \\
(0.83)\end{array}$ & $\begin{array}{c}{[-0.09} \\
0.21]\end{array}$ & $\begin{array}{l}-0.06^{\mathrm{a}} \\
(0.93)\end{array}$ & $\begin{array}{c}{[-0.20} \\
0.08]\end{array}$ \\
\hline
\end{tabular}

Note: The items assessing support for racial minorities were standardized prior to creating the index.

Different superscripts within each row indicate significant differences between conditions.

Beliefs about interpersonal factors contributing to sexism did not significantly differ by experimental condition, although there was a marginal overall effect of condition, $F(1$, $420)=2.50, p=.083, \eta_{\mathrm{p}}{ }^{2}=.01$. Examining the simple effects, White women in the structural sexism condition were less likely to report that interpersonal factors drove gender inequality, compared with participants exposed to control information, $F(1,420)=4.02, p=.046, \eta_{\mathrm{p}}{ }^{2}=.01$, or those exposed to the interpersonal sexism prime, $F(1,420)=3.53, p=.061, \eta_{\mathrm{p}}{ }^{2}=.01$. The interpersonal sexism condition did not differ from the control condition, $F(1,420)=0.01, p=.906, \eta_{\mathrm{p}}{ }^{2}=.00$. Overall, when compared against the control condition, the infographic alleging that structural sexism drives gender inequality appeared more impactful in influencing beliefs about what drives sexism than the infographic alleging that interpersonal sexism drives gender inequality. Further, the structural sexism infographic shifted beliefs in the expected direction (towards a more structural and less interpersonal understanding of gender inequality). 


\section{Perceived Pervasiveness of Sexism}

Results for perceived pervasiveness of sexism did not reveal an omnibus main effect of experimental condition, $F(2,420)=1.94, p=.145, \eta_{\mathrm{p}}{ }^{2}=.01$. The planned follow-up contrasts revealed that White women exposed to the structural sexism infographic reported greater perceptions that sexism was pervasive, compared with White women exposed to control information, $F(1,420)=3.87, p=.050, \eta_{\mathrm{p}}{ }^{2}=.01$. No other contrasts revealed differences approaching statistical significance (control condition v. interpersonal sexism condition: $F(1$, $420)=0.76, p=.383, \eta_{\mathrm{p}}{ }^{2}=.00 ;$ structural sexism condition $\mathrm{v}$. interpersonal sexism condition, $F(1$, $\left.420)=1.21, p=.272, \eta_{\mathrm{p}}{ }^{2}=.00\right)$.

\section{Psychological Abstraction}

The analysis on the measure of psychological abstraction revealed a significant omnibus effect of experimental condition, $F(2,420)=3.59, p=.029, \eta_{\mathrm{p}}{ }^{2}=.02$. Planned contrasts revealed that White women exposed to the structural sexism infographic indicated more abstract representations of behaviors relating to collective action, compared with White women exposed to interpersonal sexism, $F(1,420)=7.11, p=.008, \eta_{\mathrm{p}}{ }^{2}=.02$. No other contrasts revealed statistically significant differences (control condition v. interpersonal sexism condition: $F(1,420)=2.38$, $p=.124, \eta_{\mathrm{p}}{ }^{2}=.01 ;$ structural sexism condition v. control condition, $F(1,420)=1.33, p=.249$, $\left.\eta_{\mathrm{p}}^{2}=.00\right)$

\section{Coalitional Attitudes}

While the omnibus test for a main effect of condition was not statistically significant, $F(2,420)=2.23, p=.109, \eta_{\mathrm{p}}^{2}=.01$, the planned contrast results were consistent with the hypothesis that salient structural discrimination facilitates support for coalitions across different forms of oppression. White women exposed to the structural sexism infographic expressed greater 
perceived similarity of discrimination experiences and support for working together with other oppressed groups, compared with those in the control condition, $F(1,420)=4.42, p=.036$,

$\eta_{\mathrm{p}}{ }^{2}=.01$. Unexpectedly, the planned contrasts did not reveal reliable differences between the coalitional attitudes expressed by women exposed to the interpersonal sexism prime, compared with either participants in the control condition, $F(1,420)=1.45, p=.230, \eta_{\mathrm{p}}{ }^{2}=.00$, or those in the structural sexism condition, $F(1,420)=0.83, p=.363, \eta_{\mathrm{p}}{ }^{2}=.00$.

\section{Support for Racial Minorities}

Contrary to the results of Study $3 \mathrm{~b}$ and to predictions, there was no omnibus effect of experimental condition on White women's support for collective action to reduce racial inequality, $F(2,420)=0.64, p=.527, \eta_{\mathrm{p}}{ }^{2}=.00$. Whether White women were exposed to information about Daylight Saving Time (the control condition), interpersonal sexism, or structural sexism did not appear to influence support for action to support racial minorities.

\section{Mediation Analyses}

To investigate whether experimental condition may influence coalitional attitudes through differences in perceived pervasiveness of sexism and/or psychological abstraction, we conducted parallel mediation analyses adapted for a multicategorical independent variable (Hayes, 2013). Specifically, we estimated the confidence intervals (based on 10,000 bootstrap resamples) of the indirect effects of two dummy (indicator) variables on expressed coalitional attitudes via perceived pervasiveness of sexism and psychological abstraction (see Figure 2). We coded to make the structural sexism condition the reference group, with one dummy indicating the control condition (Dummy 1; 100 ) and the other indicating interpersonal sexism condition (Dummy 2; 0110$)$. 


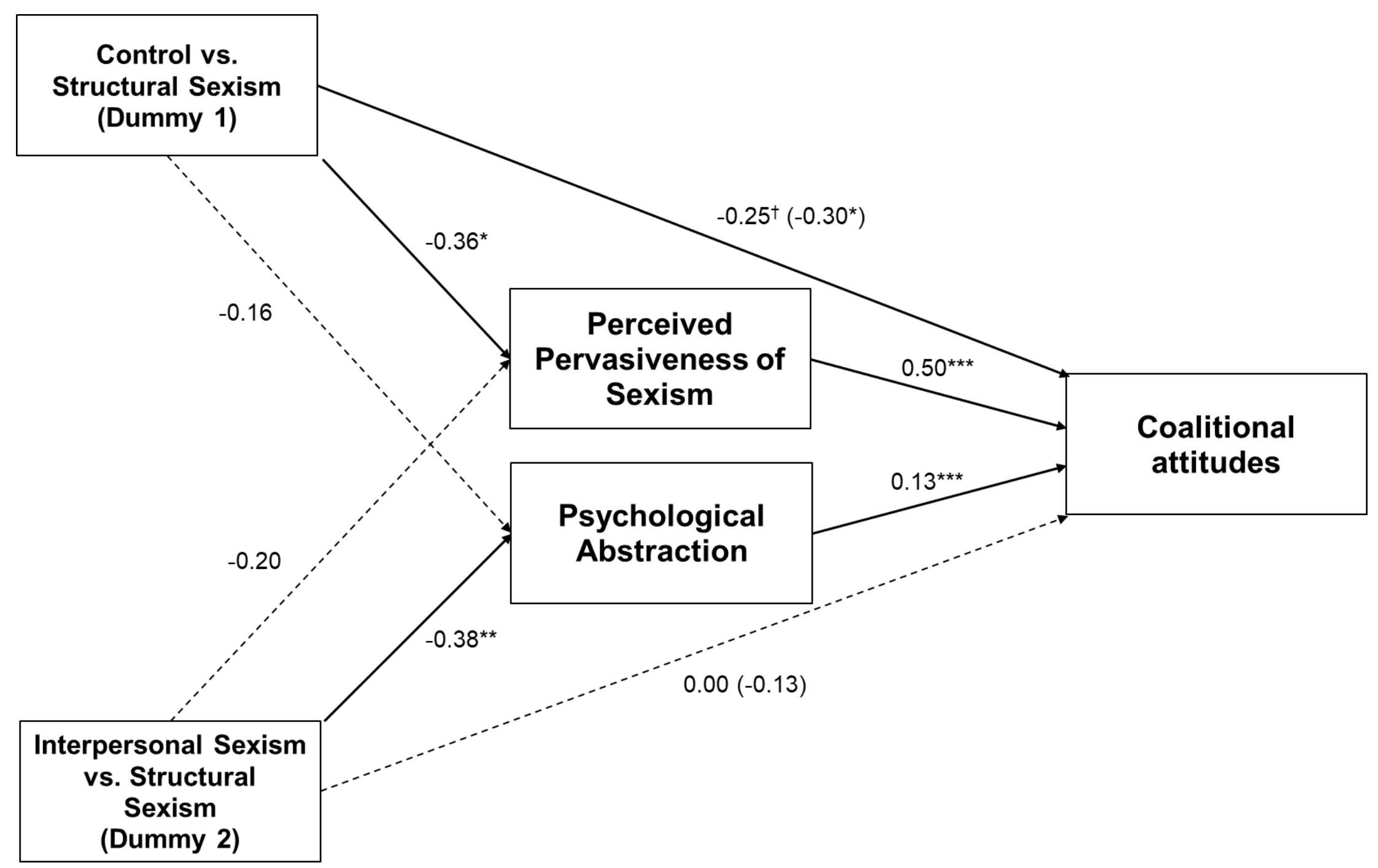

Figure 2. Parallel process model of the indirect effect of experimental condition on coalitional attitudes via perceived pervasiveness of sexism and psychological abstraction. Dummy 1 provides the contrast between the control condition and structural sexism. Dummy 2 contrasts interpersonal sexism with structural sexism. Significant effects are represented by solid arrows, whereas non-significant effects are represented by dashed arrows. The values in parentheses represent the total effects prior to the inclusion of the mediators. ${ }^{*} p<.050,{ }^{* *} p<.010,{ }^{* * *} p<.001,{ }^{\dagger} p<.100$ 
Analyses revealed two reliable indirect effects. First, White women exposed to information about structural sexism expressed more abstract conceptions of collective action (compared with participants exposed to interpersonal sexism), and in turn, this predicted more coalitional attitudes, $b=-0.05(S E=0.03), 95 \%$ CI $[-0.118,-0.011]$. Additionally, White women exposed to information about structural sexism expressed greater perceived pervasiveness of sexism (compared with participants exposed to control information about the deleterious effects of Daylight Saving Time), and in turn, this predicted more coalitional attitudes, $b=-0.18$ $(S E=0.09), 95 \% \mathrm{CI}[-0.365,-0.003]$. In contrast, we did not find a reliable indirect effect via psychological abstraction for the control v. structural comparison, $b=-0.02(S E=0.02), 95 \% \mathrm{CI}[-$ 0.071, 0.008], nor did a reliable indirect effect via perceived pervasiveness emerge for the interpersonal v. structural comparison, $b=-0.10(S E=.09), 95 \% \mathrm{CI}[-0.279,0.065]$. These separate indirect effects imply that multiple mechanisms may underlie why structural sexism information increases support for coalitions, depending on the comparison condition. In other words, compared with viewing information about interpersonal sexism, viewing information alleging that structural discrimination drives gender inequality led White women to represent collective action at a higher level of psychological abstraction, which in turn facilitated greater coalitional attitudes. In contrast, structural sexism facilitated greater coalitional attitudes via greater perceptions that sexism is pervasive if compared with responses among those for whom sexism was not salient.

\section{Discussion}

Overall, Study 4 provides further experimental evidence that making salient structural aspects of discrimination against one's own group can facilitate coalitional attitudes. Study 4 also 
tested two plausible mechanisms — perceived pervasiveness of discrimination and psychological abstraction - finding evidence that both account for the effects of salient structural discrimination on coalitional attitudes. White women who viewed information about the ways in which institutional and structural factors contribute to gender inequality indicated holding more abstract representations of collective action behavior as well as greater perceptions that sexism is a pervasive societal issue, compared with women exposed to information suggesting that interpersonal bias drives gender inequality or those exposed to control information, respectively. In turn, conceptualizing collective action behavior at higher levels of abstraction and perceiving greater pervasiveness of sexism both predicted greater perceived similarity between types of oppression and support for working together with other oppressed groups (coalitional attitudes). Thus, the present data point to both perceived pervasiveness of discrimination and psychological abstraction as plausible mechanisms through which structural lay theories of inequality may facilitate coalitional attitudes.

Another strength of Study 4 was the inclusion of a third, control condition that allowed for inferences to be drawn regarding baseline beliefs. Prior to data collection we preregistered anticipating that the new control condition mean would lie between the structural and interpersonal condition means, the data revealed a different pattern. That is, in Study 4, White women exposed to the control infographic in which sexism was not mentioned, participants' beliefs about gender inequality were reliably influenced by the structural sexism information, but not by exposure to information about interpersonal sexism. Overall, the results of Study 4 suggested that perceptions that gender inequality is driven by interpersonal discrimination may be the baseline lay theory among White women in this sample and, further, that making structural contributions to gender inequality salient can shift beliefs away from an interpersonal 
conception and heighten structural conceptions, facilitating coalitional attitudes.

While we found results consistent with Study 3 and our predictions for the measure of coalitional attitudes, unexpectedly, in Study 4 the experimental condition did not reliably influence support for taking action to address racial inequality. This was counter to expectations, to the experimental results of Study $3 b$, and to the correlational results of Studies $1-2$. Given the consistent effects on the coalitional attitudes items, which asked individuals to report their support for coalescing with other oppressed groups, it is possible that we did not assess support for collective action directed towards the oppressed group that participants had in mind when responding to the coalitional attitudes scale. For example, perhaps when reporting that women should join with oppressed groups, participants in our studies considered other, more similarlystereotyped groups (e.g., gay men). Thus, this study reveals a reliable effect of structural understandings of discrimination on coalitional attitudes, but some ambiguity remains regarding the target of those coalitional tendencies.

\section{General Discussion}

Across four studies incorporating eight distinct data sets $(N=8150)$, beliefs that structural discrimination drives ingroup inequality were associated with and led to expressed coalitional attitudes and support for other stigmatized groups. Solidarity was revealed in stated support for an activist organization supporting another stigmatized group (S1a), the extent to which issues seen as affecting another stigmatized group were discussed (S1b) and prioritized (S1c), as well as support for participating in protests and petitions to support other stigmatized groups (S2). These associations and effects appear to be quite robust and were found among multiple samples and operationalized in multiple converging ways. Overall, structural forms of discrimination can play an especially pernicious role in perpetuating inequality (e.g., Bonilla-Silva, 2006; Link \& Phelan, 
2001; Pager \& Shepherd, 2008; Salter et al., 2018) and the present work reveals that shifting individuals' beliefs toward considering structural discrimination affecting one's own group may facilitate support for coalitions among stigmatized groups to address multiple forms of inequality.

\section{Underlying Psychological Mechanisms Revisited}

In addition to consistently demonstrating that considering structural factors contributing to ingroup inequality can facilitate perceived commonality and support for coalescing among members of different stigmatized groups, the present research revealed promising initial evidence of psychological mechanisms underlying this effect. These data are consistent with the possibility that a more structural understanding of discrimination highlights the broader, societal implications and effects of discrimination, and changes the level of abstraction at which one considers the experience of group disadvantage and how to address it, especially when comparing to a focus on interpersonal sexism. Additionally, this work also suggests that a more structural understanding of discrimination can increase perceptions of pervasiveness and scope of inequality, which accounted for the greater support for intra-minority coalitions compared with a no-discrimination control condition.

Additional research would help to provide further evidence of mechanism. For example, experimentally manipulating construal level prior to providing structural discrimination information (or not) would provide strong causal support for the role of psychological abstraction driving the effect of structural discrimination on support for intra-minority coalitions. Additionally, if a more structural understanding of discrimination increases the perceived scope and pervasiveness of discrimination, leading to a greater perceived need for coalescing among members of different stigmatized groups as the issue looms larger and requires additional effort, 
then enhancing perceptions of ingroup efficacy may temper against coalitional impulses. In sum, future research is needed to continue to systematically and experimentally test the mechanisms accounting for the consistent effects identified in the present work.

\section{With Which Stigmatized Group do Individuals Seek Coalitions?}

The present research assessed two primary outcome measures of interest: coalitional attitudes, in which participants reported support for coalescing with unspecified oppressed outgroups, as well as intergroup solidarity, in which individuals were asked the degree to which they supported actions and groups that supported stigmatized outgroups. Studies 1 and 2 provided correlational evidence in support of the possibility that structural understandings of ingroup inequality are linked to White women's, LGBTQ individuals', and racial minorities' expressed solidarity with other stigmatized groups, however, this association may be relatively more difficult to achieve in a brief experimental paradigm. For example, in Studies 3-4 making structural sexism salient led White women to reliably express more coalitional attitudes, but we cannot yet make strong causal inferences regarding the effects of salient structural sexism on White women's support for taking action in support of racial minorities, in particular. We chose racial minorities as the stigmatized outgroup of interest for Studies 3-4 because they face quite distinct stereotypes and experiences with discrimination from White women and thus represent a conservative test of the hypotheses. Taken together, this work suggests that information about structural discrimination can shift individuals' beliefs about what drives inequality and consistently elicits more coalitional tendencies; however, the target of those tendencies may not be as easily-predicted. Thus, an essential future direction for research is to examine what factors contribute to the selection of preferred coalition partners.

\section{Downstream Implications}


In addition to the attitudinal and behavioral effects relating to collective action observed in the present work, individuals' lay theories of ingroup discrimination may also have downstream consequences for legal decision making. That is, structural conceptions of one's own group's discrimination may influence legal judgments affecting another stigmatized group. For example, in employment discrimination cases, different legal theories of discrimination (U.S. Equal Employment Opportunity Commission, 2010) align well with the distinction made between interpersonal discrimination (i.e., disparate treatment) and structural discrimination (i.e., disparate impact) within the social sciences. Consistent with prior work examining support for an ingroup member claiming discrimination (Blodorn et al., 2012), individuals with structural lay theories of ingroup inequality may also reach more favorable verdicts for stigmatized outgroup claimants in disparate impact discrimination cases, compared with individuals holding more interpersonal understandings. Future work is needed to explore these and other intriguing possibilities suggested by the present research.

\section{Conclusion}

Despite growing political mobilization and influence of members of different stigmatized groups, psychological research examining the dynamics of intergroup relations and support for collective action among members of different stigmatized groups is still nascent. The present research builds upon extant theorizing (e.g., Craig \& Richeson, 2016; Vollhardt, 2015) to develop a more comprehensive model of intergroup relations among members of different stigmatized groups. Whereas past research has often focused on identifying the conditions under which different ways of thinking about interpersonal discrimination can influence intergroup solidarity, the present work highlights how thinking about the structural forces that contribute to ingroup inequality and discrimination can powerfully influence relations with other stigmatized 
groups. As issues pertaining to systemic inequalities faced by different stigmatized groups reach the forefront of the national conversation, a better understanding of how considering different forms of discrimination shape stigmatized group members' interest in forming coalitions and taking action in solidarity with other stigmatized groups to address inequalities is essential for predicting future political and intergroup dynamics. 


\section{Open Practices}

Data for Studies 2-4 will be made publicly available on OSF after acceptance (it is currently available to reviewers). The preregistration document for Study 4 can be found here:

http://aspredicted.org/blind.php? $\mathrm{x}=\mathrm{cv} 55 \mathrm{z} 7$. 


\section{References}

Adams, G., Edkins, V., Lacka, D., Pickett, K., \& Cheryan, S. (2008). Teaching about racism: pernicious implications of the standard portrayal. Basic Applied Social Psychology, 30, 349-361.

Blodorn, A., O’Brien, L. T., \& Kordys, J. (2012). Responding to sex-based discrimination: Gender differences in perceived discrimination and implications for legal decision making. Group Processes and Intergroup Relations, 15, 409-424.

Bobo, L. D. (2001). Racial attitudes and relations at the close of the twentieth century. In N. J. Smelser, W. J. Wilson, F. Mitchell (Eds.), America Becoming: Racial Trends and Their Consequences. Volume 1 (pp. 264-301). National Academy Press.

Bonilla-Silva, E. (2006). Racism without racists: Color-blind racism and the persistence of racial inequality in the United States. Lanham: Rowman \& Littlefield Publishers, Inc.

Bonilla-Silva, E. (2015). The structure of racism in color-blind, "Post-racial" America. American Behavioral Scientist, 59(11), 1358-1376.

Broomfield, M. (2017, January 23). Women's March against Donald Trump is the largest day of protests in US history, say political scientists. The Independent. https://www.independent.co.uk/news/world/americas/womens-march-anti-donald-trumpwomens-rights-largest-protest-demonstration-us-history-political-a7541081.html

Brysbaert, M., Warriner, A. B., \& Kuperman, V. (2014). Concreteness ratings for 40 thousand generally known English word lemmas. Behavioral Research Methods, 46(3), 904-911.

Cortland, C. I., Craig, M. A., Shapiro, J. R., Richeson, J. A., Neel, R., \& Goldstein, N. J. (2017). Solidarity through shared disadvantage: Highlighting shared experiences of 
discrimination improves relations between stigmatized groups. Journal of Personality and Social Psychology, 113(4), 547-567.

Craig, M. A., DeHart, T., Richeson, J. A., \& Fiedorowicz, L. (2012). Do unto others as others have done unto you? Perceiving sexism influences women's evaluations of stigmatized racial groups. Personality and Social Psychology Bulletin, 38(9), 1107-1119.

Craig, M. A., \& Richeson, J. A. (2012). Coalition or derogation? How perceived discrimination influences intraminority intergroup relations. Journal of Personality and Social Psychology, 102(4), 759-777.

Craig, M. A., \& Richeson, J. A. (2014). Discrimination divides across identity dimensions: Perceived racism reduces support for gay rights and increases anti-gay bias. Journal of Experimental Social Psychology, 55, 169-174.

Craig, M. A., \& Richeson, J. A. (2016). Stigma-based solidarity: Understanding the psychological foundations of conflict \& coalition among members of different stigmatized groups. Current Directions in Psychological Science, 25(1), 21-27.

Craig, M. A., Zou, L. X., Bai, H., \& Lee, M. M. (2020). Stereotypes about political attitudes and alliances among U.S. racial groups: Implications for strategic political decision-making [Manuscript in preparation].

Curtin, N., Kende, A., \& Kende, J. (2016). Navigating multiple identities: The simultaneous influence of advantaged and disadvantaged identities on politicization and activism. Journal of Social Issues, 72(2), 264-285.

Curtin, N., Stewart, A. J., \& Cole, E. R. (2015). Challenging the status quo: The role of intersectional awareness in activism for social change and pro-social intergroup attitudes. Psychology of Women Quarterly, 39(4), 512-529. 
Hayes, A. F. (2013). Introduction to mediation, moderation, and conditional process analysis: A regression-based approach. New York: The Guilford Press.

Liberman, N., \& Trope, Y. (2008). The psychology of transcending the here and now. Science. $322,1201-1205$.

Link, B. G., \& Phelan, J. C. (2001). Conceptualizing stigma. Annual Review of Sociology, 27, $363-385$.

Nelson, J. C., Adams, G., \& Salter, P. S. (2013). The Marley hypothesis: Racism denial reflects ignorance of history. Psychological Science, 24, 213-218.

Neville, H. A., Coleman, M. N., Falconer, J. W., \& Holmes, D. (2005). Color-blind racial ideology and psychological false consciousness among African Americans. Journal of Black Psychology, 31(1), 27-45.

O’Brien, L. T., Blodorn, A., Alsbrooks, A., Dube, R., Adams, G., \& Nelson, J. C. (2009). Understanding White Americans' perceptions of racism in Hurricane Katrina-related events. Group Processes \& Intergroup Relations, 12(4), 431-444.

Pager, D., \& Shepherd, H. (2008). The sociology of discrimination: Racial discrimination in employment, housing, credit, and consumer markets. Annual Review of Sociology, 34, $181-209$.

Pérez, E. O. (2010). Explicit evidence on the import of implicit attitudes: The IAT and immigration policy judgments. Political Behavior, 32, 517-545.

Pincus, F. L. (1996). Discrimination comes in many forms: Individual, institutional, and structural. American Behavioral Scientist, 40(2), 186-194. 
Richeson, J. A., \& Craig, M. A. (2011). Intra-minority intergroup relations in the twenty-first century. Daedalus, the Journal of the American Academy of Arts \& Sciences, 140(2), $166-175$.

Rucker, J. M., Duker, A., \& Richeson, J. A. (2020). Structurally unjust: How lay beliefs about racism relate to perceptions of and responses to racial inequality in criminal justice [Manuscript in preparation].

Salter, P. S., Adams, G., \& Perez, M. J. (2018). Racism in the structure of everyday worlds: A cultural-psychological perspective. Current Directions in Psychological Science, 27(3), 150-155.

Sellers, R. M., Rowley, S. A. J., Chavous, T. M., Shelton, J. N., \& Smith, M. A. (1997). Multidimensional inventory of Black identity: A preliminary investigation of reliability and construct validity. Journal of Personality and Social Psychology, 73(4), 805-815.

Tawa, J., Suyemoto, K. L., \& Roemer, L. (2012). Implications of perceived interpersonal and structural racism for Asian Americans' self-esteem. Basic and Applied Social Psychology, 34(4), 349-358.

Trope, Y., \& Liberman, N. (2010). Construal-level theory of psychological distance. Psychological Review, 117(2), 440-463.

Unzueta, M., \& Lowery, B. S. (2008). Defining racism safely: The role of self-image maintenance on White Americans' conceptions of racism. Journal of Experimental Social Psychology, 44(6), 1491-1497.

U. S. Equal Employment Opportunity Commission (n.d.). Sex-Based Discrimination. https://www.eeoc.gov/laws/types/sex.cfm 
U. S. Equal Employment Opportunity Commission (2010). Employment Tests and Selection Procedures. https://www.eeoc.gov/policy/docs/factemployment_procedures.html

Utsey, S. O., Ponterotto, J. G., Reynolds, A. L., \& Cancelli, A. A. (2000). Racial discrimination, coping, life satisfaction, and self-esteem among African Americans. Journal of Counseling \& Development, 78(1), 72-80.

Vollhardt, J. R., Nair, R., \& Tropp, L. R. (2016). Inclusive victim consciousness predicts minority group members' support for refugees and immigrants. Journal of Applied Social Psychology, 46(6), 345-368.

Vollhardt, J. R. (2015). Inclusive victim consciousness in advocacy, social movements, and intergroup relations: Promises and pitfalls. Social Issues and Policy Review, 9(1), 89120. 


\section{Footnotes}

${ }^{1}$ Additional information on the methodology and full questionnaires can be found here: S1a: https://www.kff.org/report-section/survey-of-americans-on-race-methodology/, S1b: http://www.pewsocialtrends.org/2016/06/27/methodology-6/, S1c: http://www.peoplepress.org/dataset/december-2017-political-survey/. For the remaining studies, unless otherwise noted, we report all measures, manipulations and exclusions.

${ }^{2}$ We do not have data for participants' membership (or lack thereof) in these groups.

${ }^{3}$ Study $3 \mathrm{a}$ also included measures of prejudice toward Black Americans and gay people and Study $3 \mathrm{~b}$ included an exploratory measure of perceptions of legal situations that we are pursuing as part of ongoing research. 


\section{Supplemental Materials}

\section{Lay Theories of Discrimination Measures (Studies 1-4)}

Study 1a

Which of the following do you think is the bigger problem in America today?

$1=$ Discrimination that is historically built into our society and institutions

$0=$ Individuals'own beliefs and prejudices that cause them to treat those of other races poorly

\section{Study $1 b$}

When it comes to discrimination against black people in our country today, which do you think is the bigger problem?

$1=$ Discrimination that is built into our laws and institutions

$0=$ Discrimination that is based on the prejudice of individual people

\section{Study 1c}

Which comes closer to your view about recent allegations of sexual harassment and assault?

$1=$ They are mainly isolated incidents of individual misconduct

$0=$ They mainly reflect widespread problems in society

Studies 2a, 3, \& 4

$(1=$ Strongly disagree, $7=$ Strongly agree $)$

\section{Structural Beliefs about Sexism}

1. Most of the discrimination that women face stems from policies that, even if unintentional, disproportionately disadvantage women.

2. Sexism is primarily caused by institutional practices that [happen to] disadvantage women.* *bracketed text included in Study 2 a only

\section{Interpersonal Beliefs about Sexism}

1. Sexism is primarily caused by sexist individuals who have negative attitudes toward women.

2. Most of the discrimination that women face stems from interacting with sexist people.

\section{Study $2 b$}

$(1=$ Strongly disagree, $7=$ Strongly agree $)$

\section{Structural Beliefs about LGBTQ Discrimination}

1. Most of the discrimination that LGBTQ individuals face stems from policies that, even if unintentional, disproportionately disadvantage LGBTQ people.

2. LGBTQ inequality is mostly caused by institutional practices that disadvantage LGBTQ individuals.

\section{Interpersonal Beliefs about LGBTQ Discrimination}

1. LGBTQ inequality is mostly caused by prejudiced individuals who have negative attitudes.

2. Most of the discrimination that LGBTQ individuals face stems from interacting with prejudiced people. 


\section{Coalitional Attitudes Measures (Studies 2-4)}

\section{Study $2 a$}

Instructions

Do you belong to at least one group (e.g., ethnic, gender, sexual orientation, religious) that has faced discrimination in the past or is currently discriminated against? Yes No If so, which group(s)?

Please think of this group/these groups when indicating your agreement with the following statements:

$\begin{array}{ccccccc}\text { Strongly } & \text { Somewhat } & \text { Slightly } & \text { Neither Agree } & \text { Slightly } & \text { Somewhat } & \text { Strongly } \\ \text { Disagree } & \text { Disagree } & \text { Disagree } & \text { nor Disagree } & \text { Agree } & \text { Agree } & \text { Agree } \\ 1 & 2 & 3 & 4 & 5 & 6 & 7\end{array}$

1. The same forces which have led to the oppression of my group have also led to the oppression of other groups.

2. The struggle for my group's equality in America should be closely related to the struggle of other oppressed groups.

3. People from my group should learn about the oppression of other groups.

4. People from my group should treat other oppressed people as allies.

5. The discrimination my group has experienced is similar to that of other minority groups.

6. There are other people who experience injustice and indignities similar to my group.

7. People from my group will be more successful in achieving their goals if they form coalitions with other oppressed groups.

8. People from my group should try to become friends with people from other oppressed groups.

9. The dominant society devalues anything not White male oriented.

\section{Study $2 b$}

Instructions

Please indicate your level of agreement or disagreement with the following statements:

$\begin{array}{ccccccc}\text { Strongly } & \text { Somewhat } & \text { Slightly } & \text { Neither Agree } & \text { Slightly } & \text { Somewhat } & \text { Strongly } \\ \text { Disagree } & \text { Disagree } & \text { Disagree } & \text { nor Disagree } & \text { Agree } & \text { Agree } & \text { Agree } \\ 1 & 2 & 3 & 4 & 5 & 6 & 7\end{array}$

1. LGBTQ individuals should learn about the oppression of other groups.

2. LGBTQ individuals should treat other oppressed people as allies.

3. The discrimination LGBTQ individuals have experienced is similar to that of other minority groups.

4. LGBTQ individuals will be more successful in achieving their goals if they form coalitions with other oppressed groups.

5. LGBTQ individuals should try to become friends with people from other oppressed groups.

Study 3 \& Study 4 
Instructions

Please indicate your level of agreement or disagreement with the following statements:

1. The same forces which have led to women's oppression have also led to the oppression of other groups.

2. The struggle for women's equality in America should be closely related to the struggle of other oppressed groups.

3. Women should learn about the oppression of other groups.

4. Women should treat other oppressed people as allies.

5. The discrimination that women have experienced is similar to that of other minority groups.

6. There are other people who experience injustice and indignities similar to women.

7. Women will be more successful in achieving their goals if they form coalitions with other oppressed groups.

8. Women should try to become friends with people from other oppressed groups.

9. The dominant society devalues anything not White male oriented.

\section{Solidarity Measures}

\section{Study 1a}

Do you consider yourself to be a supporter of the Black Lives Matter movement, or not?

$1=$ Yes, supporter of the Black Lives Matter Movement

$0=$ No, not a supporter of the Black Lives Matter Movement

\section{Study $1 b$}

Now I am going to read a list of things that have been in the news recently. For each, please tell me how often, if ever, it comes up in your conversations with family and friends. What about immigration? Do you talk about this often, sometimes, rarely, or never?

$1=$ Never

$2=$ Rarely

$3=$ Sometimes

$4=$ Often

\section{Study 1c}

In general, do you think there is too much, too little, or about the right amount of attention paid to race and racial issues in our country these days?

$1=$ Too much attention

$2=$ About the right amount of attention

$3=$ Too little attention

\section{Study 2b: Attitudinal Measure}

Instructions

Please indicate how much you support or oppose the following:

$\begin{array}{ccccccc}\text { Strongly } & \text { Somewhat } & \text { Slightly } & \text { Neither Oppose } & \text { Slightly } & \text { Somewhat } & \text { Strongly } \\ \text { Oppose } & \text { Oppose } & \text { Oppose } & \text { nor Support } & \text { Support } & \text { Support } & \text { Support } \\ 1 & 2 & 3 & 4 & 5 & 6 & 7\end{array}$


1. What is your opinion on requiring race-based affirmative action for university admissions?

2. What is your opinion on raising taxes to fund reparations for Black Americans?

3. What is your opinion on the Black Lives Matter movement?

4. What is your opinion on requiring employers to make special efforts to recruit Black workers?

5. What is your opinion on increasing funding to Historically-Black Colleges and Universities (HBCUs)?

Study 2b: Behavioral Petition-Signing Measure

You now have the opportunity to sign a petition in support of the following causes. Please scan the QR code below and check which petition you wish to sign (if any).

Racial Inequality

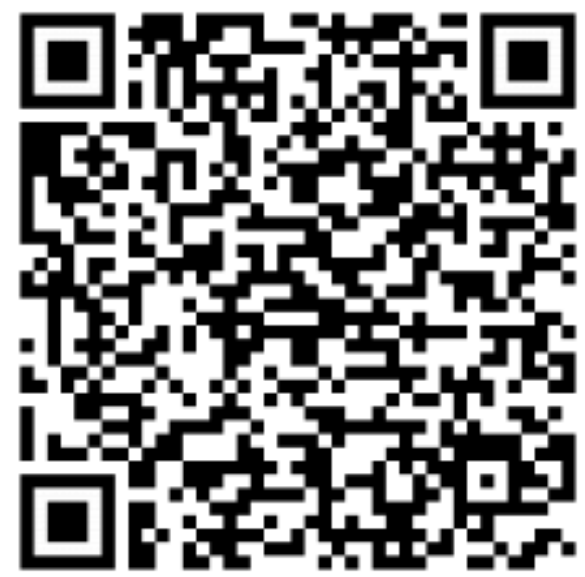

Support Reparations for Black America
LGBTQ Inequality

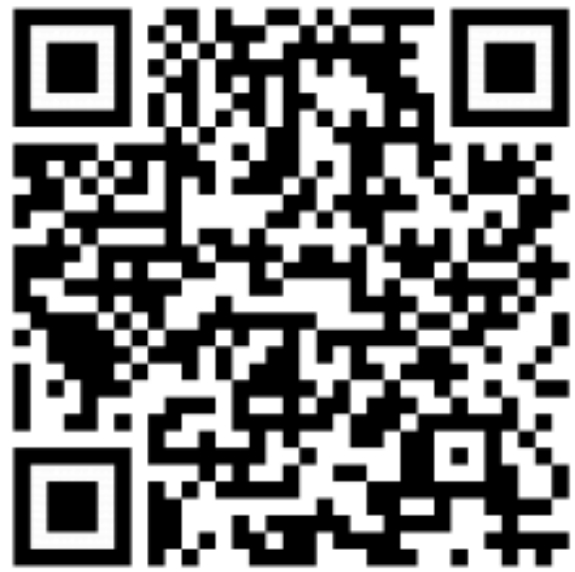

Support the Equality Act

Studies $3 b$ \& 4

1. How do you feel about the Black Lives Matter movement?

$(1=$ Strongly oppose, 7 = Strongly support $)$

2. Are you willing to sign a petition to pledge your support to reduce racial inequality in the US?

$(1=$ Extremely unwilling, 7 = Extremely willing $)$

3. What is the likelihood that you would attend a protest or demonstration to support racial minorities?

$(1=$ Extremely unlikely, $7=$ Extremely likely $)$

Mediator Measures (Study 4) 


\section{Perceived Pervasiveness of Discrimination}

$(1$ = Strongly disagree, 7 = Strongly agree $)$

1. Sexism is a big problem in the United States

2. Sexism in the United States occurs in rare, isolated situations (reverse-coded)

\section{Psychological Abstraction Measure}

Instructions

Any behavior can be identified in many ways. For example, one person might describe a behavior as "washing clothes," while another might describe the behavior as "putting clothes into the machine." Yet another person might describe the behavior as "removing odors from clothes." We are interested in your personal preferences for how a number of different behaviors should be described. Following these instructions, you will find several different behaviors listed and two choices of different ways in which the behavior might be identified.

Your task is to mark where, between the two identifications listed, the target behavior fits best to you. Simply indicate the number that most closely represents where the behavior belongs, based on how similar it seems to each of the listed identifications. You may choose any point between the two for each behavior. Of course, there are no right or wrong answers. People simply differ in their preferences for the different behavior descriptions, and we are interested in your personal preferences.

Voting (1 = Influencing the election, 7 = Marking a ballot $)$

Protesting $(1=$ Expressing one's values, $7=$ Shouting $)$

Attending a rally $(1=$ Standing with others, $7=$ Being supportive of a cause $)$

Resisting (1 = Saying "no", 7 = Showing moral courage $)$

Signing a petition $(1=$ Expressing support for a cause, $7=$ Writing one's name on paper $)$

Forming a coalition $(1=$ Working in a group with other people, $7=$ Acting in solidarity $)$

Facing discrimination $(1=$ Experiencing societal devaluation, $7=$ Being treated poorly by another person) 
Study 3

\section{Experimental Manipulations}

\section{Structural Infographic Prime}

\section{NEW RESEARCH ON GENDER INEQUALITY}

INSTITUTIONAL SEXISM DRIVES GENDER INEQUALITY
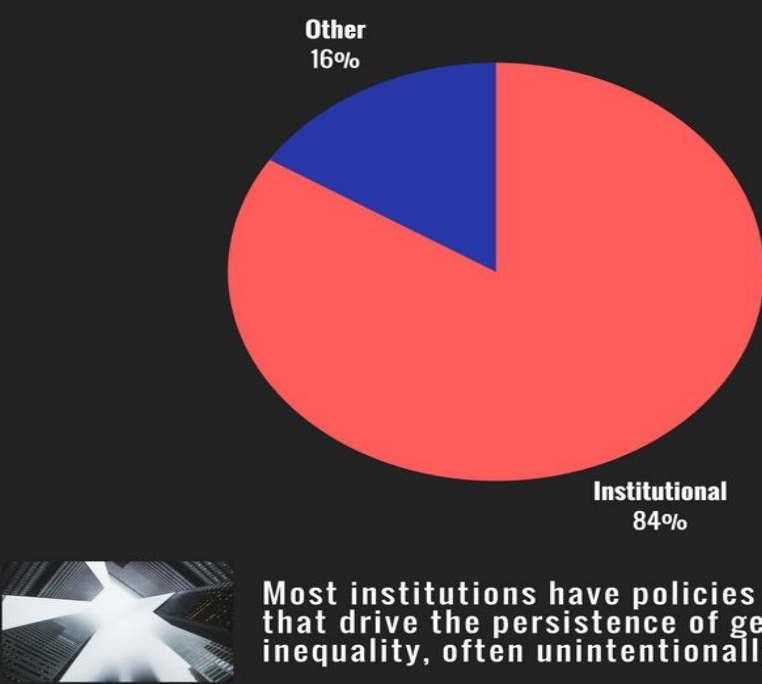

Most institutions have policies and practices that drive the persistence of gender inequality, often unintentionally

$78 \%$ of people report encountering institutional practices (e.g., laws, policies) that perpetuate gender inequality in the last month
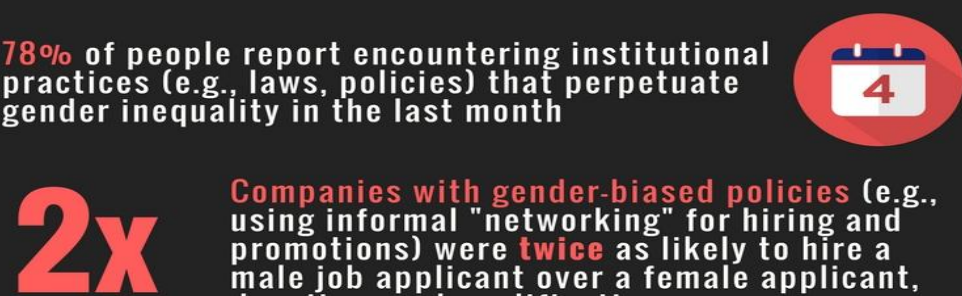

Companies with gender-biased policies (e.g., using informal "networking" for hiring and promotions) were twies as likely to hire a male job applicant over a female applicant. despite equal qualifications

Institutional policies and practices drive the gender pay gap, in which women are

currently paid $83 \%$ of what equally-qualified men are paid

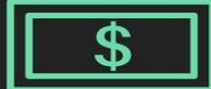

Institutional gender bias has stayed

surprising stable over time---a 2016 study

revealed a majority of companies had policies

that disadvantage women 


\section{NEW RESEARCH ON GENDER INEQUALITY}

\section{INTERPERSONAL SEXISM DRIVES GENDER INEQUALITY}

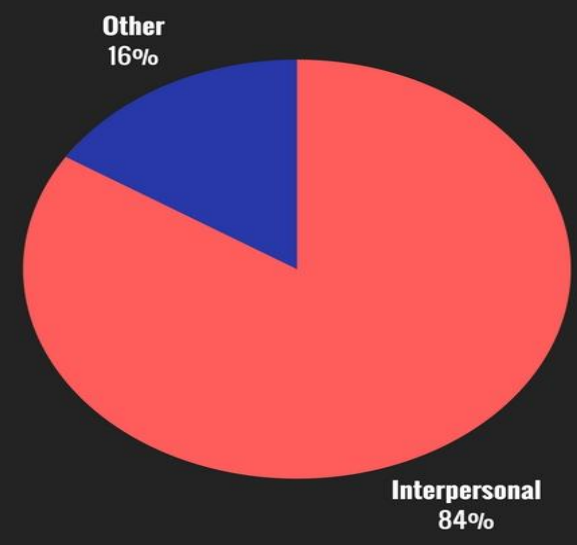

Most individuals harbor fairly high levels of gender bias, often at unconscious levels of awareness

$78 \%$ of people report witnessing someone say something sexist either in-person or online in the last month
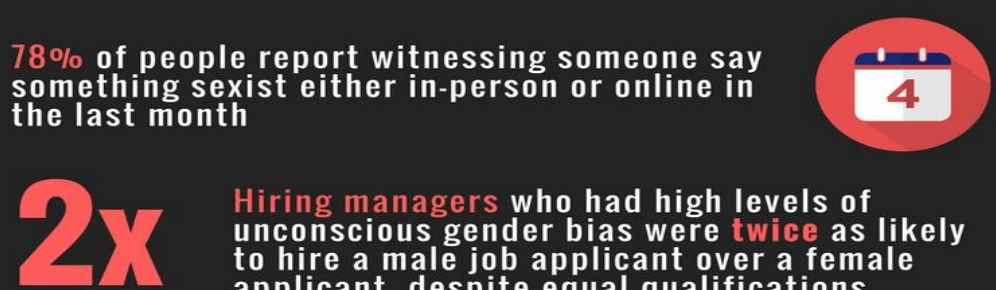

Hiring managers who had high levels of unconscious gender bias were twioe as likely to hire a male job applicant over a female applicant, despite equal qualifications

Negative attitudes \& stereotypes drive the gender pay gap, in which women are currently paid $83 \%$ of what equally-qualified men are
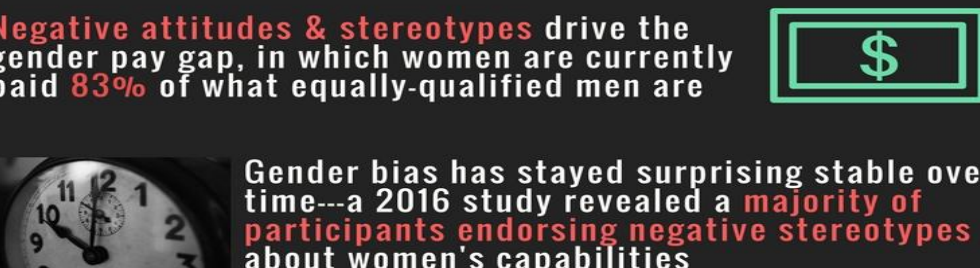

Gender bias has stayed surprising stable over time---a 2016 study revealed a majority of participants endorsing negative stereotypes about women's capabilities 


\section{Study 4}

\section{Structural Infographic Prime}

\section{NEW RESEARCH ON GENDER INEQUALITY}

\section{INSTITUTIONAL SEXISM DRIVES GENDER INEQUALITY}

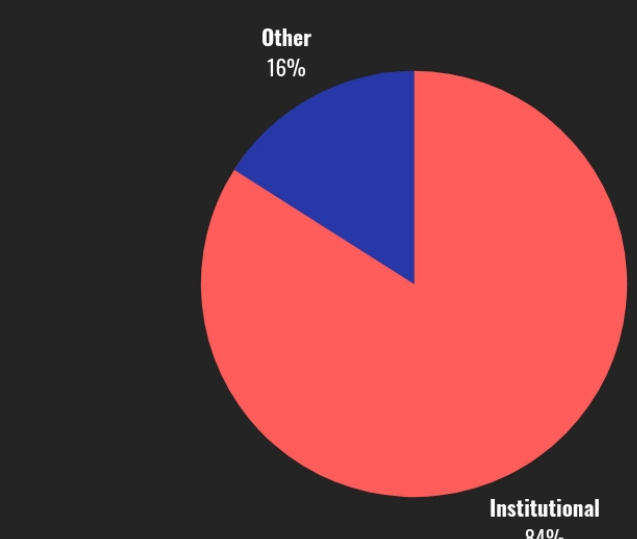

$84 \%$

Most institutions have policies and practices that drive the persistence of gender inequality, often unintentionally

$78 \%$ of people report encountering institutional practices (e.g., laws, policies) that perpetuate gender inequality in the last month

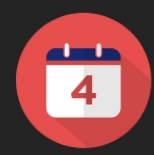

$$
\begin{aligned}
& \text { Companies with gender-biased policies (e.g., } \\
& \text { using informal "networking" for hiring and } \\
& \text { promotions) were twice as likely to hire a } \\
& \text { male job applicant over a female applicant, } \\
& \text { despite equal qualifications }
\end{aligned}
$$

Institutional policies and practices drive the gender pay gap, in which women are currently paid $83 \%$ of what equally-qualified men are paid
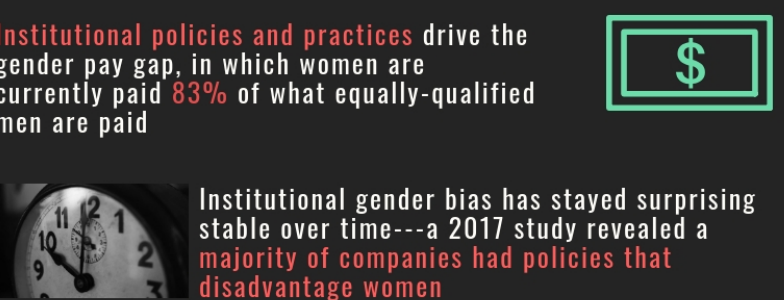


\section{Interpersonal Infographic Prime}

\section{NEW RESEARCH ON GENDER INEQUALITY}

\section{INTERPERSONAL SEXISM DRIVES GENDER INEQUALITY}

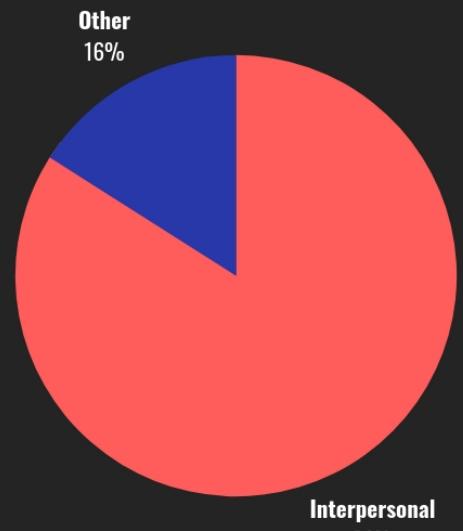

$84 \%$

Most individuals act in ways that drive the persistence of gender inequality, often unintentionally due to unconscious gender bias

$78 \%$ of people report witnessing someone say something sexist either in-person or online in the last month
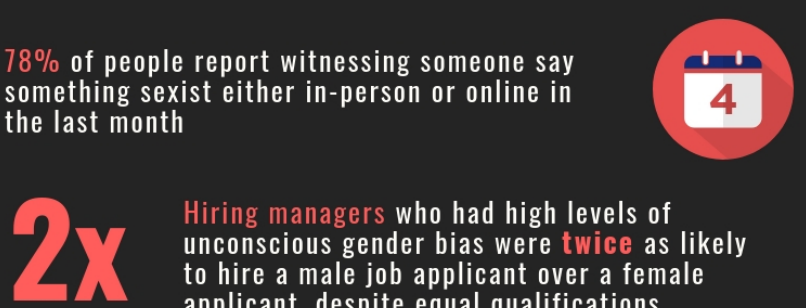
Hiring managers who had high levels of unconscious gender bias were twice as likely to hire a male job applicant over a female applicant, despite equal qualifications

Negative attitudes \& stereotypes drive the gender pay gap, in which women are currently paid $83 \%$ of what equally-qualified men are

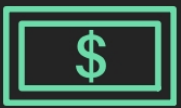

Gender bias has stayed surprising stable over time---a 2017 study revealed a majority of participants endorsing negative stereotypes about women's capabilities 


\section{Control Infographic Prime}

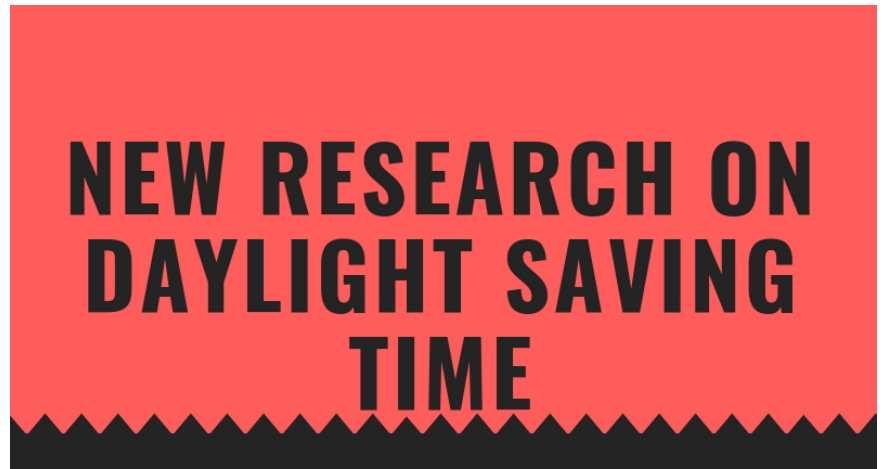

\section{SLEEP DISRUPTION DRIVES ACCIDENTS} FOLLOWING DAYLIGHT SAVING TIME

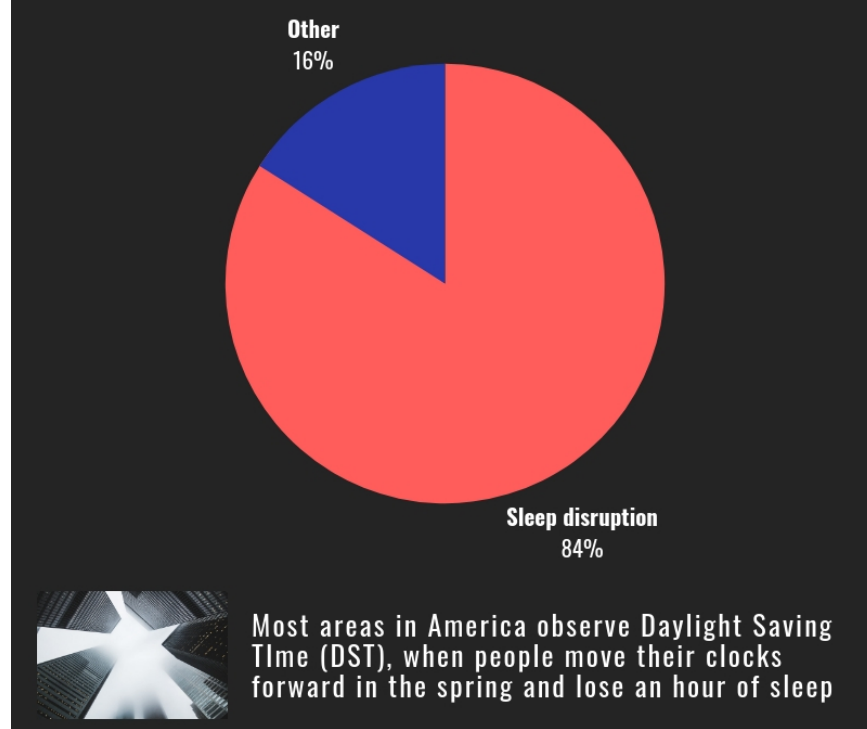

$78 \%$ of people report experiencing "negative" or "very negative" sleep disruptions surrounding the switch to DST

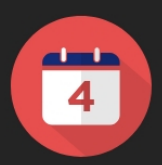

\section{The likelihood of having a car or household \\ accident was twice as likely in the days \\ immediately after changing clocks forward for DST}

Several U.S. states and territories operate on their own clocks, but $83 \%$ of states
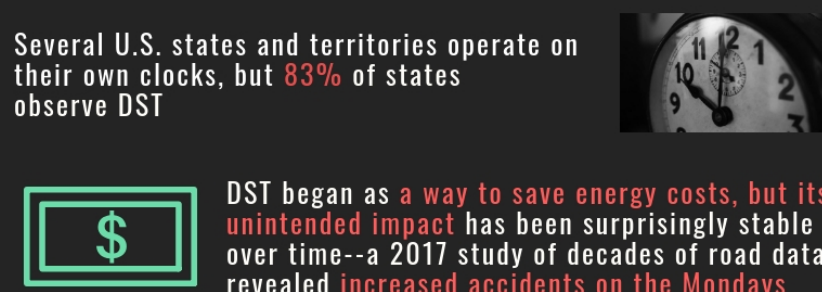

DST began as a way to save energy costs, but its unintended impact has been surprisingly stable over time--a 2017 study of decades of road data revealed increased accidents on the Mondays after the shift 


\section{Additional Analyses and Study Information Studies 1a and 1b Additional Analyses}

Studies 1a and 1b (but not Study 1c) also assessed respondents' perceptions that they personally faced discrimination. Conceptually replicating prior research (Craig \& Richeson, 2012), perceptions that respondents faced racial discrimination predicted Hispanic Americans' support for BLM, S1a: $b=0.34(S E=0.15), t=2.22, p=.026, O R=1.40,95 \% \mathrm{CI}[1.04,1.89]$, and Black Americans' discussion of immigration, S1b: $b=0.22(S E=0.03), t=6.24, p<.001 r_{\text {partial }}=.21$, $95 \% \mathrm{CI}[.18, .24]$, controlling for political ideology and demographic characteristics. Importantly, even controlling for political ideology, demographic characteristics, and perceptions of personal experiences with discrimination, respondents with more structural (vs. interpersonal) views of racism reported greater support for BLM, $b=0.66(S E=.27), t=2.48, p=.013, O R=1.93$, $95 \% \mathrm{CI}[1.15,3.25]$ and greater discussion of immigration [S1b: $b=0.20(S E=.07), t=2.81, p=.005$, $\left.r_{\text {partial }}=.10,95 \% \mathrm{CI}[.07, .13]\right]$. Thus, the observed associations reported in the main text are not likely to be attributable to a tendency for individuals with a structural view of racism to also perceive that they personally face more discrimination.

\section{Study 2a: Additional Sample Context}

For Study 2a, we initially sought to compare the beliefs and attitudes of White women who were actively engaged in collective action for their own group (i.e., those participating in a protest about gender inequality) to a sample of women in the same public space under normal (non-protest) conditions to provide a breadth of ideological viewpoints within the sample.

Unfortunately, given the challenges associated with collecting data in a time-sensitive protest, the sample does not have a sufficiently large subsample of protesters to make well-powered comparisons across subsamples (25 protesters, 39 general population), so we collapsed across this distinction in the main text. 
Exploratory analyses revealed that protesters reported a more structural understanding of sexism $(M=6.08 S D=0.76)$, compared with the non-protest sample $(M=5.38, S D=1.04), t(62)=$ $2.88, p=.005, d=0.74$. However, intriguingly, interpersonal sexism beliefs did not vary by sample (protest: $M=3.88, S D=1.72$; general: $M=3.81, S D=1.50), t(62)<1, p=.860, d=0.05$. White women engaged in a protest also were more likely to express that oppressions are linked and different oppressed groups should coalesce $(M=6.30, S D=0.82)$, compared with White women in the area in a normal (non-protest) context $(M=5.58, S D=0.98), t(60)=3.02, p=.004, d$ $=0.78$.

\section{Study 2b: Additional Study Context}

In Study 2b, we attempted and failed to manipulate lay theories of inequality (structural or interpersonal) with a brief manipulation of the pen-and-paper survey. Participants were randomly-assigned to indicate how familiar they were with either four structural LGBTQ discrimination facts (structural condition) or four interpersonal LGBTQ discrimination facts (interpersonal condition; $1=$ Not at all familiar, 5=Very familiar). For example, participants read that "Thirty states do not have legal protections that allow LGBTQ people to bring forward a claim of discrimination in the workplace" (structural condition) or "Many employers deny employment and refuse raises and promotions to LGBTQ people because of their sexual orientation or gender identity without legal ramifications" (interpersonal condition). All participants read about discrimination affecting the ingroup (anti-LGBTQ discrimination), but whether structural or interpersonal forms of discrimination were described varied across experimental condition. Participants reported greater familiarity with interpersonal ( $M=3.70$, $S D=0.99)$ than structural $(M=2.79, S D=1.04)$ examples of bias, $t(140)=5.31, p<.001$. 
Beliefs that LGBTQ discrimination is due to structural factors or interpersonal factors were not significantly affected by the experimental manipulation, $t(140)=0.17, p=.863$ and $t(140)=0.17, p=.867$, respectively. While unexpected, we speculate that the manipulation failure occurred because of the subtle nature of the manipulation. Thus, we collapsed across this distinction and used the lay theories of inequality scales as correlational predictors for the analyses reported in the main text. 